\title{
A Rapid Review on Community Connected Microgrids
}

\author{
Moiz Masood Syed *(D) and Gregory M. Morrison (ID
}

check for

updates

Citation: Syed, M.M.; Morrison, G.M. A Rapid Review on Community Connected Microgrids. Sustainability 2021, 13, 6753. https://doi.org/ $10.3390 /$ su13126753

Academic Editor: Tomonobu Senjyu

Received: 9 May 2021

Accepted: 14 June 2021

Published: 15 June 2021

Publisher's Note: MDPI stays neutral with regard to jurisdictional claims in published maps and institutional affiliations.

Copyright: (c) 2021 by the authors. Licensee MDPI, Basel, Switzerland. This article is an open access article distributed under the terms and conditions of the Creative Commons Attribution (CC BY) license (https:// creativecommons.org/licenses/by/ $4.0 /)$.
School of Design and the Built Environment, Curtin University Sustainability Policy Institute, Curtin University, Perth 6102, Australia; greg.morrison@curtin.edu.au

* Correspondence: m.syed13@postgrad.curtin.edu.au; Tel.: +61-416-500-270

\begin{abstract}
As the population of urban areas continues to grow, and construction of multi-unit developments surges in response, building energy use demand has increased accordingly and solutions are needed to offset electricity used from the grid. Renewable energy systems in the form of microgrids, and grid-connected solar PV-storage are considered primary solutions for powering residential developments. The primary objectives for commissioning such systems include significant electricity cost reductions and carbon emissions abatement. Despite the proliferation of renewables, the uptake of solar and battery storage systems in communities and multi-residential buildings are less researched in the literature, and many uncertainties remain in terms of providing an optimal solution. This literature review uses the rapid review technique, an industry and societal issue-based version of the systematic literature review, to identify the case for microgrids for multi-residential buildings and communities. The study describes the rapid review methodology in detail and discusses and examines the configurations and methodologies for microgrids.
\end{abstract}

Keywords: rapid review; microgrid; community; solar PV; battery storage; utility grid; inverter; energy sharing

\section{Introduction}

Electricity produced from non-renewable power plants can experience power disruptions because of extreme weather conditions, which may sometimes result in huge financial losses [1], estimated at USD 44 billion annually, as reported in the US [2]. At the same time, the recent upsurge of solar photovoltaic (PV) penetration worldwide, coupled with the climate agenda of carbon emissions mitigation, have also disrupted the monopoly of fossil fuel-based power plants, thus transitioning towards a new renewable power regime.

Following the suppression of socio-economic activity induced by COVID-19, there was a decline of $6.4 \%$ in global greenhouse gas (GHG) emissions in 2020 relative to 2019, equivalent to 2.3 billion tonnes [3]. Although this reduction is promising, GHG emissions are expected to surpass previous figures when the ongoing pandemic situation comes to an end. Of the reported 33 billion tonnes of global GHG emissions for the 2019 season [4], along with other active sources of emissions, the building sector is a key contributor; it has been reported that the building sector is responsible for $19 \%$ of carbon emissions, $51 \%$ of global electricity consumption and 32\% of global energy consumption $[5,6]$.

It is commonly acknowledged that the main drivers of electricity consumption of buildings are heating and cooling appliances. Although modification in construction design can modulate these loads, such high consumption offers an excellent opportunity for the abatement of GHG emissions and costs by utilising distributed renewable energy sources (DRESs).

It is financially difficult to accomplish net zero energy in existing residential buildings, but there are approaches to offset grid-imported electricity, with innovative building construction designs emerging. The concept of net zero energy buildings (NZEBs) has been adapted widely in the research community and projects. NZEBs generate the energy they consume from DRESs, mainly PV and battery storage. Today, the utility network 
offers dynamic tariffs for scheduling consumers' electricity usage. Energy management systems (EMSs) and arbitrage allow users to charge their electric vehicle (EV) during low-tariff periods. These innovative measures contribute to net zero sustainable buildings. It is, however, equally important to identify which building type (detached houses, multiresidential communities or high-rise apartments) requires an identified mode of technology if the energy transition is to accelerate.

Though attractive in theory, "net zero" as such is not the cornerstone of an ideal sustainable building; rather, this lies in the combined specifics of maintaining smooth electricity supply, frequency and voltage stability, backup generation during blackouts and meeting peak demand that must be contemplated in the selection process of DRESs. For instance, diesel generators are still regarded in many applications as the most orthodox backup option to provide electricity during outages and are often combined with battery storage. However, rapid infrastructure transformation and increasing tariffs foster the need for a new electricity paradigm to deliver power, with microgrids being the product of this new required distributed transformation. Microgrids contain a group of loads and poly-generation sources (e.g., PV and battery storage) operating in a single management system connected to the grid or isolated.

The increased penetration of DRES, principally PV, into utility grids poses various challenges such as the management of excess energy flow, voltage fluctuation, frequency distortion, system stability and protection issues [7]. Further, the efficient utilisation of renewable energy is also imperative on both residential and commercial scales. Microgrids offer various benefits when integrated with the grid, including (i) energy quality, (ii) system reliability, (iii) peak power reduction, (iv) ancillary services provision such as voltage and frequency regulation, $(\mathrm{v})$ reactive power support through the injection of power into the grid, (vi) backup supply in case of grid failure, (vii) electricity infrastructure replacement, (viii) contribution to GHG abatement and (ix) providing autonomy to consumers by giving them control over modifying their energy use through demand response strategies.

The massive rollout of small-scale distributed microgrids with PV and battery storage systems can curtail the levelized cost of energy and, in some cases, cause grid parity situations [8]. The deployment of battery storage from static packs to mobile EVs can also minimise energy costs and ensure the smooth supply of power.

Indeed, various multi-objective control and optimisation techniques can be applied to model microgrids [9]. In the same manner, several forms of DRESs can be integrated with microgrids, such as fuel cells, hydrogen, wind turbines and various forms of energy storage. Technological developments and decreasing costs of DRESs favour microgrid deployment globally; however, many regulatory and policy barriers across certain domains exist, which should also be surveyed. It appears that multi-residential buildings, communities and apartments have received less attention when it comes to the applicability of DRESs, in line with their complexity in design, regulations and scalability.

After the careful review of scientific articles on the topic, it appears that there are several ways of implementing a microgrid for multi-residential buildings and communities; we define such microgrid schemes as community connected microgrids (CCMs). It is worth noting that the terms community grid, community microgrid and multi-residential communities are used interchangeably with CCM in this study without the actual meaning being affected.

The aim of this study is to contribute to existing knowledge from the perspective of a rapid review and provide an effective methodology taking into account CCMs. The scholarship is compiled through configurations or topologies related to CCM, their characteristics, methodologies, pros and cons and barriers to the operationalisation of such microgrids.

The next sections cover the methodology used to conduct the rapid review, followed by a description of the selected articles, a synopsis of configurations, methodologies, opportunities and barriers in microgrid implementation, and finally, a conclusion. 


\section{The Rapid Review Methodology}

Rapid review methodology and manuscripts accelerated over the year 2020, partly due to the emergence and prevalence of COVID-19 around the world. The principles of this methodology are based on the systematic review method, which seeks to identify the conclusions and analyses of multiple research resources, but so that the results obtained can be implemented for policymaking within shorter timeframes. To keep the research predefined and well organised, certain inclusion and exclusion criteria are set with the aim of extracting only published literature reviews from authentic and reliable resources for further evaluation.

Rapid reviews differ from standard literature reviews as such studies can be completed within shorter timeframes as compared with traditional systematic literature reviews (SLRs), which are often conducted within one to two years $[6,10]$. They have been predominantly conducted in the medical science research, and there is not much evidence that they have been applied in the field of renewable energy. Rapid reviews, much like SLRs, minimise the risk of bias [6]. Factors such as specific database selection, set timeframes and review article proclivity confines the length of rapid reviews. Rapid reviews implicitly synthesise a wide literature through original reviews without these being singularly studied. Consequently, the conclusions are much shorter; the findings, however, are substantial and unbiased as compared with narrative reviews.

We take the example of the "AGILE" model used in Lagisz et al. [11] to describe the rapid review process, in which each step is recurrent and interconnected to the following step. Although AGILE was originally developed drawing on a different motivation, it is still appropriate for use in this study, which follows the steps as shown in Figure 1. To expedite the process, we have excluded the team communication step, which often requires stakeholder consultation and interviews, from the AGILE model.

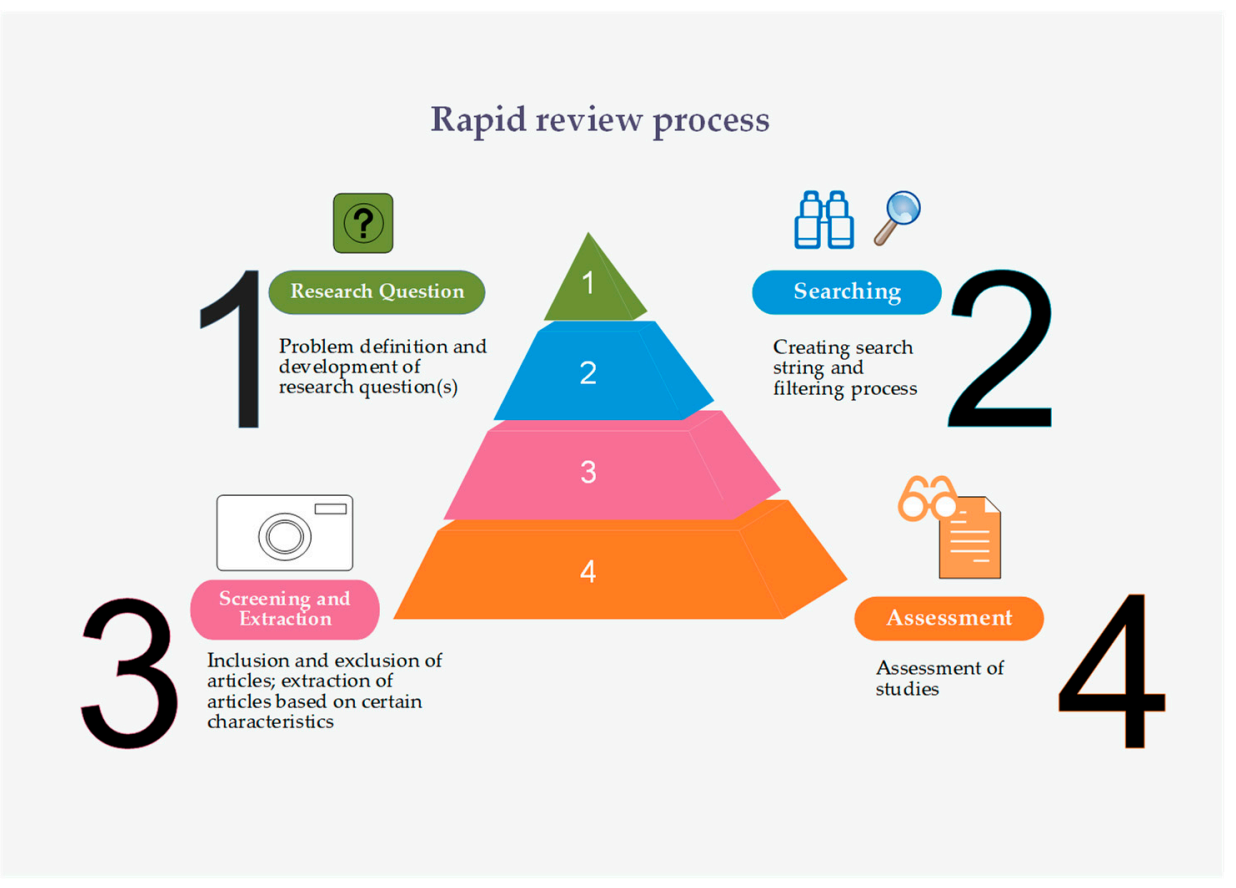

Figure 1. Rapid review process diagram.

The rapid review methodology (see Figure 1) follows the following steps:

1 Research question;

2 Search criteria and filtering method;

3 Screening, eligibility criteria and extraction;

4 Quality assessment of selected studies. 
We now discuss each step.

\subsection{Research Question}

The fundamental research questions have been designed for this rapid review in such a way that they provide a quick overview of microgrids, including configurations, methodologies used and typical challenges that the system encounters and resolves on implementation. Research questions developed before formulating the review comprise the following:

5 Which type of configuration(s) in microgrids is mainly used with DRES within CCM?

What are the characteristics, benefits and technical challenges involved?

6 Which control methodologies and optimisation were applied in CCM?

$7 \quad$ What are the main barriers to the implementation of CCM?

These research questions are not exhaustive, and the review may contain information in much more detail. As indicated earlier, our focus has been on microgrids for community and multi-residential housing. Although this article reviews without specificity regarding location, any narrative review or grey literature concentrating on a particular area and passing the assessment criteria is included in this study.

\subsection{Search Criteria and Filtering Method}

Four reliable trans-disciplinary databases-namely, Scopus, Web of Science, ProQuest and IEEE-were selected for this research. The year selection ranges from 2010 to 2020. A separate search was also conducted through Google and Google Scholar to generate results based on grey academic literature (e.g., reports and articles) that might be relevant and may not have been discovered if running only the usual academic database search. Since Google prioritises search results by number of citations, initial result pages were preferred. Publications were selected in accordance with their scope and the eligibility criteria (listed in Section 2.3), and emphasis was given to documents that contained reviews.

The criterion for the year selection was set to include only recent research studies relevant to research topic, so that the current scenario and rapidly changing technology trends and the situation regarding microgrids within multi-residential buildings could be thoroughly analysed and investigated.

The search string was tested on 15 March 2021 using the abovementioned academic databases and the results were blended to address the research questions. The search string process given in each database looks visually different; however, they follow a common sequence of steps, which are:

- $\quad$ Boolean operator usage to combine different queries, e.g., OR, AND.

- Exact search term or approximate words (with wildcard characters, e.g., "**").

- Word stemming to retrieve both singular and plural form of words.

The search method was applied to filter article titles, keywords and abstracts; other selection parameters included articles in English language, peer-reviewed academic publications, and strictly review articles.

The search string applied to the databases consisted of the following words:

(("solar" OR "solar PV" OR "PV" OR "solar*" OR "photovoltaic*" OR "microgrid" OR "microgrid*" OR "distributed*" OR "integrated") AND (batter* OR battery OR storage OR "energy storage" OR "battery storage") AND ("building*" OR "multi-residential" OR "apartment" OR community OR "communit*" OR "dwelling*" OR "storey" OR "multifamily" OR "condos" OR "suite*" OR “villa*" OR "multi-unit") AND ("systematic review" OR "systematic literature review" OR review OR "meta analysis" OR "meta-analysis"))

Appendix A lists the search string and filters applied to the different academic databases.

\subsection{Screening, Eligibility Criteria and Extraction}

The accumulated results from the database search criteria and Google/Google Scholar were forwarded to Endnote reference management, which applied the duplicate removal 
process followed by manual screening for filtering the abstracts and titles that were most relevant. Articles that qualified for the rapid review consisted of literature review articles and grey literature that addressed the research question; more specifically, the selected publications fell into one of the following categories:

- Studies that provided a thorough review on microgrids in communities and multiresidential buildings.

- Studies that explored energy system configurations and discussed opportunities as well as challenges of deploying CCM.

The relevant articles, as revealed by the abstract and title screening, were studied in detail and synthesised following the same relevancy criteria discussed previously. Among the total of 327 identified search results, after the search, filtering and eligibility process, 13 articles were considered relevant for rapid review. Figure 2 outlines the search and screening processes based on the Preferred Reporting Items for Systematic Reviews and Meta-Analyses (PRISMA) diagram.

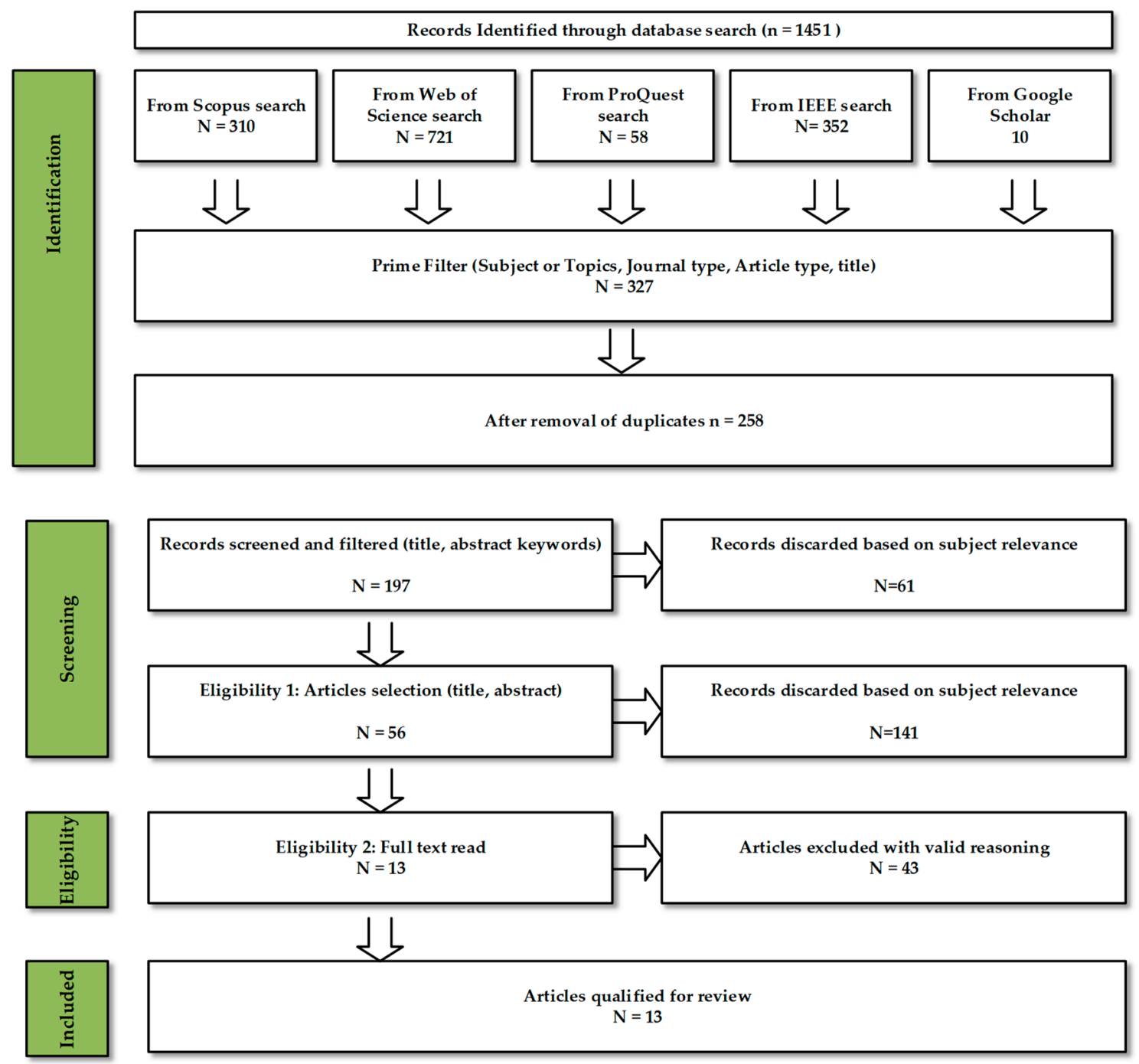

Figure 2. Article selection using the PRISMA approach to the rapid review.

\subsubsection{Extraction and Composition}

Similar to other types of review, the rapid review can be synthesised qualitatively and quantitatively depending on the characteristics of the articles [6]. Although the reviewed papers are of a technical nature, this rapid review is described qualitatively. 
The following attributes were identified for each article included in this rapid review: publication year, paper title, review type, number of reviewed articles, building type, funding and study scope. Research question data concerning microgrid configurations, methodologies and challenges were derived and synthesised.

Content included reasons for different components and configurations used for microgrids in communities, their strengths and shortcomings, challenges (technical as well as regulatory), optimisation control methodologies and future recommendations. Microgrids for communities generally operate on AC-type DRESs with or without battery storage, with the main objective of obtaining low-carbon, cheap electricity and autonomy for consumers by facilitating energy sharing and trading. At the niche level, the process involves technologies used in microgrids for power conversion, control, protection, monitoring and grid interaction. From an administrative point of view, energy management considering load demand and grid connection is also vital, as is discussed below.

\subsubsection{Quality Evaluation}

A quality evaluation of the selected publications is imperative to provide insightful results and rapid review authentication. The evaluation was conducted through A Measurement Tool to Assess Systematic Reviews version 2 (AMSTAR2) [12], which contains 16 questions to be addressed for every article (see Appendix B). The questions included in AMSTAR2 discuss search strategies, methodologies, risk of bias (RoB) evaluation and results interpretation quality. To visually validate the quality of the articles, Table 1 with answers for the 16 questions is included with colour coding: blue-accent- 1 colour represents a "yes" answer, orange-accent-2 colour represents a "no" answer and yellow indicates "unsure". Articles displaying more blue fields indicate high quality and involve lower RoB. Questions 11, 12 and 15 were not applicable and hence excluded.

\subsection{Quality Assessment of Selected Studies}

An SLR aims to collate academic evidence that meets predefined eligibility criteria for the purpose of addressing a particular research question. In comparison with narrative reviews, SLRs are considered high quality with minimal RoB. Narrative reviews, in contrast, exhibit random criteria regarding article selection, thus limiting the search methodology. Moreover, the literature selected in narrative reviews is self-selected, and hence has a high RoB.

Adhering to the eligibility criteria, all publications included in this rapid review are literature reviews (12), with one qualitative analysis report. The characteristics of each review are distinct as, among the 12 articles, only one claims to be a systematic review while 11 are narrative reviews of academic or grey literature. The AMSTAR2 risk assessment tool conducted for the 12 articles in Table 1 shows that publications included scored an average of 3.1 (out of 13 questions), implying an overall medium quality.

The highest score, achieved by Ceglia et al. (2020), was 5 (38.4\%). According to question four of Table 1, most studies did not record satisfactory information regarding their comprehensive literature search strategy and data extraction procedures. Moreover, a majority disregarded the quality and RoB of the examined reviews. 
Table 1. Quality evaluation of questions from the AMSTAR 2 checklist. The character " $Q$ " in "Q1-Q16" of Table 1 denotes question number.

\begin{tabular}{ccccccccccccccc}
\hline Author (Year) & Q1 & Q2 & Q3 & Q4 & Q5 & Q6 & Q7 & Q8 & Q9 & Q10 & Q13 & Q14 & Q16 & $\begin{array}{c}\text { Overall } \\
\text { Score }\end{array}$ \\
\hline Zou, Mao [13] & 1 & 0 & 0 & 0 & 0 & 0 & 0 & 0.5 & 0 & 0 & 0 & 0.5 & 1 \\
\hline $\begin{array}{c}\text { Burmester, } \\
\text { Rayudu [14] }\end{array}$ & 0.5 & 0 & 0 & 0 & 0 & 0 & 0 & 0.5 & 0 & 0 & 0 & 0.5 & 1 \\
\hline Hannan, Faisal [15] & 1 & 0 & 0 & 0 & 0 & 0 & 0 & 0.5 & 0 & 0 & 0 & 1 & 1 & 3.5 \\
\hline Planas, Andreu [16] & 1 & 0 & 0 & 0 & 0 & 0 & 0 & 0.5 & 0 & 0 & 0 & 0.5 & 1 \\
\hline $\begin{array}{c}\text { Parra, } \\
\text { Swierczynski [17] }\end{array}$ & 1 & 0 & 0 & 0 & 0 & 0 & 0 & 0.5 & 0 & 0 & 0 & 0.5 & 1 \\
\hline Huang, Zhang [18] & 1 & 0 & 0.5 & 0 & 0 & 0 & 0 & 0.5 & 0.5 & 0 & 0 & 0.5 & 1 \\
\hline Koirala, Koliou [19] & 1 & 0.5 & 0.5 & 0 & 0 & 0 & 0.5 & 0.5 & 0.5 & 0 & 0 & 0.5 & 0 \\
\hline Neves, Silva [20] & 1 & 0 & 0.5 & 0 & 0 & 0 & 0 & 0.5 & 0.5 & 0 & 0 & 0.5 & 1 \\
\hline $\begin{array}{c}\text { Rosado and } \\
\text { Khadem [21] }\end{array}$ & 0.5 & 0 & 0 & 0 & 0 & 0 & 0 & 0 & 0 & 0 & 0 & 0 & 0 \\
\hline Ceglia, Esposito [22] & 1 & 0.5 & 1 & 0.5 & 0 & 0 & 0 & 0.5 & 0 & 0 & 0 & 0.5 & 1 \\
\hline Roberts, Bruce [23] & 1 & 0 & 0 & 0 & 0 & 0 & 0 & 0.5 & 0 & 0 & 0 & 0.5 & 1 \\
\hline Olgyay, Coan [24] & 0.5 & 0 & 0 & 0 & 0 & 0 & 0 & 0.5 & 0 & 0 & 0 & 0.5 & 1 \\
\hline
\end{tabular}

Huang, Zhang [18] claimed to be a systematic review; however, it neither followed a literature strategy nor defined any exclusion criteria, and only partially discussed RoB assessment. Koirala, Koliou [19] performed a database search, but without explaining further steps of a systematic review. Only one article [22] discussed the selection criteria of the study design and review method; a few other studies discussed this in vague terms. Three articles partially discussed RoB. Ceglia, Esposito [22] mentioned more than two databases and keywords for the article search, but nevertheless lacked information usually presented in a thorough systematic review. The majority of the selected articles discussed summarised results based on scholarship retrieved from review articles, albeit without considering RoB. Taking all these limitations into account, this rapid review discusses the important and relevant outcomes and conclusions.

\section{Study Characteristics}

The papers reviewed in this rapid review were published between 2010 and 2020; altogether, they reviewed approximately 1700 research articles, case studies and grey literature. They were written globally, spanning Europe, Asia, Africa, Australia and North America. The main theme of the reviewed articles was microgrid configurations or energy systems for communities and multi-residential buildings.

Table 2 lists the study characteristics of the reviewed articles. Four articles [13,14,16,25] explicitly investigated microgrids, particularly in the domain of energy management, configurations, control topologies and design and modelling challenges. The remaining articles focused on DRESs for community setup. 
Table 2. Characteristics of the reviewed articles.

\begin{tabular}{|c|c|c|c|c|c|c|c|c|}
\hline Author & Title & $\begin{array}{l}\text { Article } \\
\text { Type }\end{array}$ & Study Scope & $\begin{array}{l}\text { Building } \\
\text { Type }\end{array}$ & Location & $\begin{array}{c}\text { Number of } \\
\text { Reviewed } \\
\text { Studies }\end{array}$ & Research Funding & $\begin{array}{l}\text { Conflict } \\
\text { of } \\
\text { Interests }\end{array}$ \\
\hline $\begin{array}{c}\text { Zou, } \\
\text { Mao [13] }\end{array}$ & $\begin{array}{l}\text { A Survey of Energy } \\
\text { Management in } \\
\text { Interconnected } \\
\text { Multi-Microgrids }\end{array}$ & $\begin{array}{l}\text { Narrative } \\
\text { review }\end{array}$ & $\begin{array}{l}\text { Review of surveys regarding } \\
\text { energy management systems } \\
\text { (EMSs) in multi-microgrids and } \\
\text { review on the optimisation } \\
\text { algorithm. }\end{array}$ & $\begin{array}{l}\text { Interconnected } \\
\text { households }\end{array}$ & $\begin{array}{l}\text { Researchers are based } \\
\text { in China and the US; } \\
\text { article locations not } \\
\text { specified }\end{array}$ & $\begin{array}{l}\text { Not explicitly } \\
\text { stated }\end{array}$ & $\begin{array}{c}\text { NSF China, Central } \\
\text { Universities of China, US } \\
\text { NSF and WEREC, } \\
\text { Auburn University US }\end{array}$ & None \\
\hline $\begin{array}{l}\text { Burmester, } \\
\text { Rayudu [14] }\end{array}$ & $\begin{array}{l}\text { A Review of Nanogrid } \\
\text { Topologies and } \\
\text { Technologies }\end{array}$ & $\begin{array}{l}\text { Narrative } \\
\text { review }\end{array}$ & $\begin{array}{l}\text { Reviews the nanogrid, its control } \\
\text { topologies and usefulness within } \\
\text { supply and demand domain. }\end{array}$ & $\begin{array}{l}\text { Multiple } \\
\text { loads }\end{array}$ & $\begin{array}{l}\text { Researchers are based } \\
\text { in New Zealand; } \\
\text { article location is not } \\
\text { specified }\end{array}$ & $\begin{array}{l}\text { Not explicitly } \\
\text { stated }\end{array}$ & $\begin{array}{l}\text { Victoria University } \\
\text { Wellington }\end{array}$ & None \\
\hline $\begin{array}{l}\text { Hannan, } \\
\text { Faisal [15] }\end{array}$ & $\begin{array}{l}\text { A Review of Internet of } \\
\text { Energy (IoE) Based } \\
\text { Building Energy } \\
\text { Management Systems: } \\
\text { Issues and } \\
\text { Recommendations }\end{array}$ & $\begin{array}{l}\text { Narrative } \\
\text { review }\end{array}$ & $\begin{array}{l}\text { Review of an IoE-based BEMS for } \\
\text { improving the future generation } \\
\text { building performance and energy } \\
\text { utilisation. }\end{array}$ & NZEB & $\begin{array}{l}\text { Researchers are based } \\
\text { in Malaysia, Australia } \\
\text { and Denmark; article } \\
\text { locations not specified }\end{array}$ & $\begin{array}{l}\text { Not explicitly } \\
\text { stated }\end{array}$ & $\begin{array}{c}\text { Universiti Tenaga } \\
\text { Nasional }\end{array}$ & None \\
\hline $\begin{array}{l}\text { Parra, Swier- } \\
\text { czynski [17] }\end{array}$ & $\begin{array}{l}\text { An Interdisciplinary } \\
\text { Review of Energy } \\
\text { Storage for } \\
\text { Communities: } \\
\text { Challenges } \\
\text { and Perspectives }\end{array}$ & $\begin{array}{l}\text { Narrative } \\
\text { review }\end{array}$ & $\begin{array}{l}\text { Analysis of community energy } \\
\text { system (CES) technologies, } \\
\text { applications and the role of } \\
\text { stakeholders in the deployment } \\
\text { of CES. }\end{array}$ & Communities & $\begin{array}{l}\text { Researchers are based } \\
\text { in Switzerland, the } \\
\text { UK and Denmark; } \\
\text { article locations not } \\
\text { specified }\end{array}$ & $\begin{array}{l}\text { Not explicitly } \\
\text { stated }\end{array}$ & $\begin{array}{c}\text { Commission for } \\
\text { Technology and } \\
\text { Innovation in Switzerland } \\
\text { within the Swiss } \\
\text { Competence Centre for } \\
\text { Energy Research in Heat } \\
\text { and Electricity Storage. }\end{array}$ & None \\
\hline
\end{tabular}


Table 2. Cont.

\begin{tabular}{|c|c|c|c|c|c|c|c|c|}
\hline Author & Title & $\begin{array}{l}\text { Article } \\
\text { Type }\end{array}$ & Study Scope & $\begin{array}{c}\text { Building } \\
\text { Type }\end{array}$ & Location & $\begin{array}{l}\text { Number of } \\
\text { Reviewed } \\
\text { Studies }\end{array}$ & Research Funding & $\begin{array}{l}\text { Conflict } \\
\text { of } \\
\text { Interests }\end{array}$ \\
\hline $\begin{array}{l}\text { Huang, } \\
\text { Zhang [18] }\end{array}$ & $\begin{array}{l}\text { A Technical Review of } \\
\text { Modeling Techniques } \\
\text { for Urban Solar } \\
\text { Mobility: Solar to } \\
\text { Buildings, Vehicles, and } \\
\text { Storage (S2BVS) }\end{array}$ & $\begin{array}{l}\text { Systematic } \\
\text { review }\end{array}$ & $\begin{array}{l}\text { Systematic review of solar } \\
\text { mobility research along with } \\
\text { newly developed energy } \\
\text { concepts and techniques. The } \\
\text { study discussed the conventional } \\
\text { solar mobility scope from the } \\
\text { solar to buildings, vehicles and } \\
\text { storage (S2BVS) perspective. } \\
\text { Moreover, detailed modelling of } \\
\text { each configuration in the S2BVS } \\
\text { model and related advanced } \\
\text { controls is presented. }\end{array}$ & $\begin{array}{l}\text { Residential } \\
\text { and } \\
\text { commercial } \\
\text { buildings }\end{array}$ & $\begin{array}{c}\text { Researchers are based } \\
\text { in Sweden, China and } \\
\text { the UK; article } \\
\text { locations not specified }\end{array}$ & $\begin{array}{c}\text { Mostly Europe, } \\
\text { the US, the UK } \\
\text { and East Asia } \\
\text { (China and } \\
\text { Japan) }\end{array}$ & $\begin{array}{l}\text { This research was funded } \\
\text { by the EU Horizon } 2020 \\
\text { EnergyMatching project, } \\
\text { the UBMEM project of the } \\
\text { Swedish Energy Agency } \\
\text { and the J. Gust. Richert } \\
\text { foundation in Sweden }\end{array}$ & None \\
\hline $\begin{array}{c}\text { Koirala, } \\
\text { Koliou [19] }\end{array}$ & $\begin{array}{c}\text { Energetic Communities } \\
\text { for Community Energy: } \\
\text { A Review of Key Issues } \\
\text { and Trends Shaping } \\
\text { Integrated Community } \\
\text { Energy Systems }\end{array}$ & $\begin{array}{l}\text { Narrative } \\
\text { review }\end{array}$ & $\begin{array}{l}\text { Presents the concept of ICES. } \\
\text { Reviews the recent energy trends } \\
\text { and the related technological, } \\
\text { socio-economic, environmental } \\
\text { and institutional problems } \\
\text { forming the development of } \\
\text { ICESs. It discusses the role of } \\
\text { local systems to incorporate } \\
\text { DRESs while engaging local } \\
\text { communities. }\end{array}$ & Communities & $\begin{array}{l}\text { Researchers are based } \\
\text { in the Netherlands, } \\
\text { Spain and Germany; } \\
\text { article locations not } \\
\text { specified }\end{array}$ & $\begin{array}{l}\text { Not explicitly } \\
\text { stated }\end{array}$ & $\begin{array}{l}\text { Erasmus Mundus } \\
\text { Fellowship }\end{array}$ & None \\
\hline $\begin{array}{l}\text { Neves, } \\
\text { Silva [20] }\end{array}$ & $\begin{array}{c}\text { Design and } \\
\text { Implementation of } \\
\text { Hybrid Renewable } \\
\text { Energy Systems on } \\
\text { Micro-communities: A } \\
\text { Review on Case Studies }\end{array}$ & $\begin{array}{l}\text { Narrative } \\
\text { review of } \\
\text { case } \\
\text { studies }\end{array}$ & $\begin{array}{l}\text { Reviews the design of Hybrid } \\
\text { Renewable Energy Systems } \\
\text { (HRESs) in isolated } \\
\text { micro-communities, particularly } \\
\text { on islands. Discusses systems } \\
\text { configuration, electricity demand } \\
\text { characteristics and dynamics, and } \\
\text { complexities in implementation. }\end{array}$ & $\begin{array}{l}\text { Micro- } \\
\text { communities } \\
\text { on islands }\end{array}$ & $\begin{array}{l}\text { Researchers are based } \\
\text { in Portugal and the } \\
\text { US; article locations } \\
\text { are based in Europe, } \\
\text { Asia, Africa, Oceania } \\
\text { and North America }\end{array}$ & $\begin{array}{l}42 \text { island case } \\
\text { studies and } 7 \\
\text { remote villages }\end{array}$ & $\begin{array}{c}\text { Foundation of Science } \\
\text { and Technology of } \\
\text { Portugal }\end{array}$ & None \\
\hline
\end{tabular}


Table 2. Cont.

\begin{tabular}{|c|c|c|c|c|c|c|c|c|}
\hline Author & Title & $\begin{array}{l}\text { Article } \\
\text { Type }\end{array}$ & Study Scope & $\begin{array}{l}\text { Building } \\
\text { Type }\end{array}$ & Location & $\begin{array}{c}\text { Number of } \\
\text { Reviewed } \\
\text { Studies }\end{array}$ & Research Funding & $\begin{array}{c}\text { Conflict } \\
\text { of } \\
\text { Interests }\end{array}$ \\
\hline $\begin{array}{l}\text { Rosado and } \\
\text { Khadem [21] }\end{array}$ & $\begin{array}{c}\text { Development of } \\
\text { Community Grid: } \\
\text { Review of Technical } \\
\text { Issues and Challenges }\end{array}$ & $\begin{array}{l}\text { Narrative } \\
\text { review }\end{array}$ & $\begin{array}{l}\text { Reviews the technical issues } \\
\text { related to the community grid } \\
\text { scenario and approaches to } \\
\text { solutions required for the } \\
\text { purpose of making the } \\
\text { community grid highly } \\
\text { renewable and sustainable. }\end{array}$ & $\begin{array}{l}\text { Community } \\
\text { based }\end{array}$ & $\begin{array}{l}\text { Researchers are based } \\
\text { in Ireland; article } \\
\text { locations are based in } \\
\text { Europe, Asia, Africa, } \\
\text { Oceania and North } \\
\text { America }\end{array}$ & Not stated & Not given & None \\
\hline $\begin{array}{c}\text { Ceglia, } \\
\text { Esposito [22] }\end{array}$ & $\begin{array}{l}\text { From Smart Energy } \\
\text { Community to Smart } \\
\text { Energy Municipalities: } \\
\text { Literature Review, } \\
\text { Agendas and Pathways }\end{array}$ & $\begin{array}{l}\text { Narrative } \\
\text { review }\end{array}$ & $\begin{array}{c}\text { Examines the theoretical } \\
\text { approach of smart energy } \\
\text { community and discussed } \\
\text { incentives of smart energy } \\
\text { community applications in smart } \\
\text { localities. }\end{array}$ & $\begin{array}{l}\text { Community } \\
\text { based }\end{array}$ & $\begin{array}{l}\text { Researchers are based } \\
\text { in Italy; location of } \\
\text { every article is not } \\
\text { given, however, some } \\
\text { articles are based in } \\
\text { Japan and Europe. }\end{array}$ & $\begin{array}{l}\text { Not explicitly } \\
\text { stated but only } \\
10 \text { energy } \\
\text { communities } \\
\text { mentioned in a } \\
\text { table }\end{array}$ & $\begin{array}{l}\text { Regione Campania, } \\
\text { within the framework of } \\
\text { the GeoGRID ProjecT }\end{array}$ & None \\
\hline $\begin{array}{c}\text { Roberts, } \\
\text { Bruce [23] }\end{array}$ & $\begin{array}{l}\text { Opportunities and } \\
\text { Barriers for } \\
\text { Photovoltaics on } \\
\text { Multi-unit Residential } \\
\text { Buildings: Reviewing } \\
\text { the Australian } \\
\text { Experience }\end{array}$ & $\begin{array}{l}\text { Narrative } \\
\text { review }\end{array}$ & $\begin{array}{c}\text { Reviews opportunities and } \\
\text { barriers to increasing PV } \\
\text { deployment in apartment } \\
\text { buildings. }\end{array}$ & Apartments & $\begin{array}{c}\text { Researchers are based } \\
\text { in Australia; content } \\
\text { locations are mostly } \\
\text { Australian }\end{array}$ & $\begin{array}{l}\text { Combination } \\
\text { of } 44 \text { articles, } \\
\text { several survey } \\
\text { reports and } \\
\text { regulatory doc- } \\
\text { umentation }\end{array}$ & $\begin{array}{c}\text { Energy Consumers } \\
\text { Australia), Co-operative } \\
\text { Research Council for Low } \\
\text { Carbon Living and an } \\
\text { Australian Government } \\
\text { Research Training } \\
\text { Program Scholarship }\end{array}$ & None \\
\hline $\begin{array}{l}\text { Olgyay, } \\
\text { Coan [24] }\end{array}$ & $\begin{array}{c}\text { Connected } \\
\text { Communities: A } \\
\text { MultiBuilding Energy } \\
\text { Management Approach }\end{array}$ & $\begin{array}{l}\text { Technical } \\
\text { report }\end{array}$ & $\begin{array}{l}\text { Explores various factors } \\
\text { influencing the development and } \\
\text { operation of connected } \\
\text { communities and assesses their } \\
\text { potential value. }\end{array}$ & $\begin{array}{c}\text { Multi- } \\
\text { buildings }\end{array}$ & $\begin{array}{l}\text { Researchers are based } \\
\text { in the US; project } \\
\text { location based in the } \\
\text { US }\end{array}$ & $\begin{array}{l}\text { Not explicitly } \\
\text { stated }\end{array}$ & $\begin{array}{c}\text { Department of Energy } \\
\text { Office of Energy } \\
\text { Efficiency and Renewable } \\
\text { Energy Building } \\
\text { Technologies Office }\end{array}$ & None \\
\hline $\begin{array}{c}\text { Fontenot and } \\
\text { Dong [25] }\end{array}$ & $\begin{array}{l}\text { Modelling and Control } \\
\text { of Building-integrated } \\
\text { Microgrids for Optimal } \\
\text { Energy } \\
\text { Management-A } \\
\text { Review }\end{array}$ & $\begin{array}{l}\text { Narrative } \\
\text { review }\end{array}$ & $\begin{array}{l}\text { Provides an outline of microgrids, } \\
\text { its components, significance to } \\
\text { utility grid and building holders. } \\
\text { It also discusses technical and } \\
\text { modeling challenges. } \\
\text { Additionally, reviews various } \\
\text { data-driven forecasting methods } \\
\text { for microgrid controls. }\end{array}$ & $\begin{array}{c}\text { General } \\
\text { buildings }\end{array}$ & $\begin{array}{l}\text { Researchers are based } \\
\text { in the US; article } \\
\text { location is not } \\
\text { specified }\end{array}$ & $\begin{array}{c}\text { Approximately } \\
177\end{array}$ & $\begin{array}{l}\text { CPS Energy and the US } \\
\text { National Science } \\
\text { Foundation }\end{array}$ & None \\
\hline
\end{tabular}


Hannan, Faisal [15] reviewed IoE-based building energy management system (BEMS) technologies such as DRESs, storage and communication interfaces for upgrading the proposed building energy operation. Community energy storage (CES) was reviewed by [17], with a strong focus on technologies used for end-user applications, techno-economic analysis and socio-environmental assessments of CES; this paper also provided a viewpoint on CES from the utility network, policy and consumers perspectives. Huang, Zhang [18] reviewed solar mobility concepts and discussed the modelling of solar to building, vehicle and storage (S2BVS). Koirala, Koliou [19] presented the concept of integrated community energy systems (ICESs) and studied issues of ICES from technical, socio-economic, environmental and institutional perspectives. Neves, Silva [20] reviewed Hybrid Renewable Energy Systems (HRESs) design for micro-communities and discussed technological configuration, electricity demand and the intricacies of system commissioning.

The concept of a community grid (CG), including grid and distributed energy sources and participation of energy trading, was presented by Rosado and Khadem [21]. The authors also presented technical issues associated with a CG and discussed solutions for developing a sustainable network. Ceglia, Esposito [22] studied smart energy systems (SESs) for smart energy communities and reviewed prospective applications in smart localities. A review by Roberts, Bruce [23] identified the scope of PV deployment in multiresidential apartment buildings and investigated opportunities and barriers for the uptake of PV systems, especially from an Australian perspective. Finally, a technical report by Olgyay, Coan [24] presented connected communities and explored several factors affecting their functionality. Nearly all articles discussed CCM, identified gaps and proposed future research directions. A summary of key findings from the reviewed articles is given in Appendix C.

\section{Community Connected Microgrids}

DRESs include distributed generators (DGs), power inverters/converters and energy storage systems (ESSs), which create a microgrid capable of feeding distributed loads. The combined effect of these components in the microgrid allows for the adequate exploitation of available resources (such as solar, wind and biomass) while improving the stability, power quality and reliability of a microgrid [16]. This section of this rapid review focuses on components of the microgrid, and configurations referred to in the review articles.

\subsection{Components of a Microgrid}

In addition to the main DRES elements stated above, other components also perform critical functions in the microgrid, including the point of common coupling (PCC), distribution, control circuit, protections and monitoring. The components of a microgrid can be operated based on different types of power source, such as AC and DC networks. Each power source offers distinct characteristics, with certain advantages and disadvantages. The microgrid can be connected and disconnected from the main grid through the PCC, which employs power converters and switchgears to perform this switchover [16].

\subsubsection{Transmission and Distribution}

AC-based microgrids consist of different types of wiring distribution contingent on the application (i.e., single, three-phase without neutral and three-phase with neutral, with three-phase being the common system for power transmission). From the regulatory point of view, the existing standards support AC microgrids for the reason that AC microgrids are ubiquitous and have broad applications, which is not the case for DC microgrids.

DC microgrids also fall into three types-mono-polar, bipolar and homo-polarand can be designed with multiple buses in order to obtain high reliability. They rely on high voltage direct current (HVDC) technology, acknowledged for its high power density, absence of short-circuit issues and high stability [16]. Prominent examples of the HVDC transmission system include the Rio Madeira system in Brazil—the longest HVDC installation, stretching over $2375 \mathrm{~km}$-and the Jinping-Sunan installation in China, 
which, with $7800 \mathrm{kV}$ ultra-HVDC [16] and a capacity of 7.2-7.6 GW, is considered the most powerful transmission line in the world.

DC distribution lines are useful when compared with AC distribution lines due to the absence of reactive power, which results in lower power losses, less voltage drop and an increased power capacity of the electrical transmission. These benefits bring about reliable and high-quality DC power output and allow a larger stretch to the network for the same capacity of load. Generally, DC/AC conversion includes electrical losses [14], while many modern sources and loads such as PV panels, batteries, compressors, fans, servers and EVs operate on DC power; hence, few studies $[14,18]$ have recommended the utilisation of DC microgrids instead of AC microgrids.

There are some instances of DC microgrid applications covered in the literature. A DC microgrid on a $350 \mathrm{~V}$ bus was proposed to introduce large PV generation in [18], which similarly reported a DC microgrid with an energy-hub for power sharing (operated at 760 $\mathrm{V})$ that converted and controlled energy flow between the DC and AC grid. A DC/DC converter was designed to step down the $760 \mathrm{~V}$ DC grid voltage to $120-400 \mathrm{~V}$ (the voltage generally required by DC loads). Thus far, the major applications of DC distribution are limited to specific areas, such as network telecommunication equipment, transportation, ships, and motors.

\subsubsection{Power Converters}

The power converters in microgrids are selected based on technical parameters such as AC or DC sources, voltage levels, the direction of power flow and, most importantly, the type of load (AC or DC). Additionally, galvanic isolation is added by using transformers. Power converters usually inject and absorb reactive power and further participate in voltage stability $[17,21,25]$. Moreover, in some cases, commercially available grid-connected PV inverters also support voltage stability, reactive power and anti-islanding functions [16].

AC systems require a controlled DC-AC inverter designed from insulated-gate bipolar transistors (IGBT), DC-DC converters and DC link capacitors for maintaining constant reference voltage at the input of inverters. Matrix converters that enable bidirectional power flow can also be used through two-way switches without the inclusion of reactive components. AC microgrids with battery storage deploy bidirectional DC-DC converter topology coupled with a three-phase transformer-based inverter [16] or, in some cases, a three-phase inverter with LC filter [21]. In DC systems, the AC source output is first converted into DC through rectifiers. Conversion is performed through a three-phase inverter coupled with a high-frequency transformer and then a three-phase rectifier. Similarly for flywheel systems, permanent synchronous generators are placed at the input of DC and AC systems.

In all DC/ AC, AC/DC and DC-DC converters, the voltage amplitude of the converters can be lower or higher than the input voltage. This variation takes effect through reactive elements (inductors or capacitors) and switching components (IGBTs). Generally, buck and boost converters are used for this purpose. Component switching is performed through pulse width modulation signals, which can also be changed by feeding back the reference voltages and currents [14].

Since DC microgrids are not generally implemented, standard power converters configurations to couple DGs into them are rare; nevertheless, they require fewer components than three-phase AC topology [16]. Furthermore, the available DC topologies utilise multilevel inverters and high-frequency transformers, which in comparison are smaller in size and lighter in weight than low-frequency transformers.

Overall, AC lines offer better conversion efficiencies than DC lines for residential systems; however, in the case of fuel cell or other DC generators, conversion efficiencies could be superior to AC. Inverters/converters deliver non-linear characteristics and carry harmonics at PCC $[15,21]$.

The presence of harmonics in the current can directly occur from converter switching, which degrades the performance of the grid because of unbalanced load conditions. Such 
harmonics can be mitigated using active and passive filters or controlling the main source of distortion. Similarly, resonances are created by the shunt capacitors in the grid. This problem is mostly found in three-phase and single-phase distribution grids. To reduce resonance, the capacitor size could be increased when designing filters [21].

Current ripple and harmonics are reduced in the DC case because of reverse polarity protection, and the ripples generated by various devices are not synchronised. Power converter/inverter topologies for PCC are proposed in [14,16].

\subsubsection{Monitoring}

To ensure balanced demand and supply, a rigid monitoring structure with a communication network is indispensable and may facilitate to apply energy management strategies. There are different monitoring interfaces used for AC and DC microgrids, as identified by [16]. One of these is a framework based on the service-oriented architecture. This interface connects different service applications via communication interfaces. A number of services can communicate with each other by either passing data or coordinating with other services. In addition, "universal monitoring, protection, and control units" considered similar to intelligent electronic devices provide efficient system monitoring, as they collect measurement data from appliances and devices. Another possibility to monitor different microgrids is via "phasor measurement units" that leverage accurate data about the power system and allow efficient management of the system.

In Hannan, Faisal [15], a BEMS is shown to incorporate data using meters and different sensors. The data are then used to analyse energy management system performance. Similarly, the field and enterprise zone of smart grid architecture in [18] consists of metering and communication equipment for the control and monitoring of electricity networks as well as power scheduling for utilities and energy traders. Metering has also been reported as one factor that has broad application in demand-side management (DSM) [19].

One of the objectives of smart communities is digital interconnectedness. This is heavily dependent on the availability of energy data flowing from cloud-based services, sensors and smart meters; however, the technical setup incurs higher installation and management costs [22]. Moreover, to incentivise consumers, measurement of parameters such as self-consumption is critical and, combined with smart metering rollout and installation in embedded networks [23], new developments are taking up metering and communication. Notwithstanding, smart metering data also raise questions of customer privacy and security of a microgrid [25]. Technology-wise, the installation of DC microgrid monitoring systems are straightforward as compared to AC microgrids due to absence of frequency and reactive power elements.

\subsubsection{Protection Schemes}

Microgrids require sophisticated protection schemes to ensure safe operation. Like transmission, protections can be based on AC and DC sources. The core criteria for selecting the proper protection systems for microgrids are sensitivity, response time and security level. The protection schemes originate from several DGs installed, and the short-circuit current availability in the islanded mode [14].

Utility standards require the implementation of anti-islanding protection schemes for power converters connected to the distribution grid. Anti-islanding schemes detect loss of utility power in a short time period and switch off the inverter in microgrid. Anti-islanding schemes may impact network performance and need enhancements to mitigate excessive trips; on the other hand, the impact of increasing PV generation can also degrade the microgrid performance with the utility network [21]. In [21], islanding detection schemes are summarised into four categories:

8 Passive: this is based on measuring the electrical magnitudes.

9 Communication-based algorithms: fast communication is provided between the grid protection and DG.

10 Active: analyses the system response while injecting the electrical current. 
11 Hybrid scheme: combines the active and passive techniques.

The protection design for DC microgrids takes a different approach than for AC microgrids because AC systems must include ground fault detection; also, since the current in DC systems omits zero crossing, short-circuit current interruption in DC systems is harder to pick up as compared with AC systems [16]. Nonetheless, protection system costs in AC microgrids are lower than in DC microgrids [16].

From a system perspective, there are protections inside inverters/converters to save the system operation; [15] mentioned fault detection and diagnosis (FDD), an automatic method of sensing and isolating faults for the protection of a BEMS.

Although IEEE set standards for protection schemes, an Australian study identified that, for bigger systems, there were no national standards for protections, and it was left to network operators to reinforce additional protection requirements for network safety [23].

\subsection{Microgrid Configurations}

Microgrids can be configured subject to the requirements of a particular site. The following subsections discuss different application-dependent configurations (mostly communities) of microgrids covered in the review articles.

\subsubsection{Behind-the-Meter Systems}

Behind-the-meter (BTM) systems are PV-based microgrids installed by an owner behind the main grid for offsetting the household electricity load. A study by [23] discussed the opportunities and barriers in implementing PV systems in apartment complexes, specifically within the Australian context. Table 3 lists the apartment installation models and the descriptions as discussed in [23].

Nevertheless, there are prevailing regulatory and governance issues associated with the adoption of shared BTM systems and shared microgrids with battery storage systems, as mentioned in [23]. The physical limitations of roof space on apartments and split incentives to proportionally distribute the incentives between the owner and renter are major governance issues. From a financial point of view, raising levies and funds for multi-residential/strata complexes and setting up internal tariffs for solar utilisation also pose challenges. Moreover, there is less data availability and knowledge gaps in research and engineering groups regarding shared BTM.

On the network side, no such retail and technical regulations exist on how to manage BTM installations. Given the applicability of shared BTM in multi-residential housing, configuration can take advantage of different governance models implemented in commercial setups, strata buildings and communities and facilitate peer-to-peer trading.

The standard configuration for PV-BTM is implemented on shared roof space of apartments to supply common property $(\mathrm{CP})$ demand connected behind the grid meter [26].

Table 3. PV implementation models for apartment buildings.

\begin{tabular}{cc}
\hline PV Implementation Models & Description \\
\hline Individual PV connected to apartments & $\begin{array}{c}\text { Does not involve shared governance and is the simplest arrangement in } \\
\text { which a PV system can be installed behind the meter. }\end{array}$ \\
\hline $\begin{array}{c}\text { Shared PV } \\
\text { Distributed arrangement to apartments using PV in an } \\
\text { embedded network }\end{array}$ & $\begin{array}{c}\text { Installation is simple and the common arrangement in shared PV is to } \\
\text { use the shared generation resource to supply CP demand. }\end{array}$ \\
\hline $\begin{array}{c}\text { Local energy trading technique to promote energy } \\
\text { trading in apartments using shared PV distribution }\end{array}$ & $\begin{array}{c}\text { Energy is distributed using the local energy trading or virtual net } \\
\text { metering method. }\end{array}$ \\
\hline $\begin{array}{c}\text { PV distribution to apartment using the } \\
\text { behind-the-meter approach }\end{array}$ & This approach involves connecting a shared PV system behind the \\
meter of all apartments.
\end{tabular}




\subsubsection{Nanogrids}

Burmester, Rayudu [14] discussed the existing literature related to nanogrids, and the techniques and control topologies that could intelligently control nanogrids. A nanogrid is defined as a power distribution system for a small building or single house with the characteristics of connecting and disconnecting from other power sources using a gateway. A local production system in nanogrid manages the control system and also utilizes energy storage. The major components of a nanogrid are shown in Figure 3. The local power source in a nanogrid could be chosen from DRESs such as wind, solar and non-renewable energy resources such as fuel cells or diesel generator. The nanogrid controller coordinates with multiple sources to optimise power and deliver it to the loads. The loads mainly consist of residential appliances such as electric heaters, ovens and televisions.

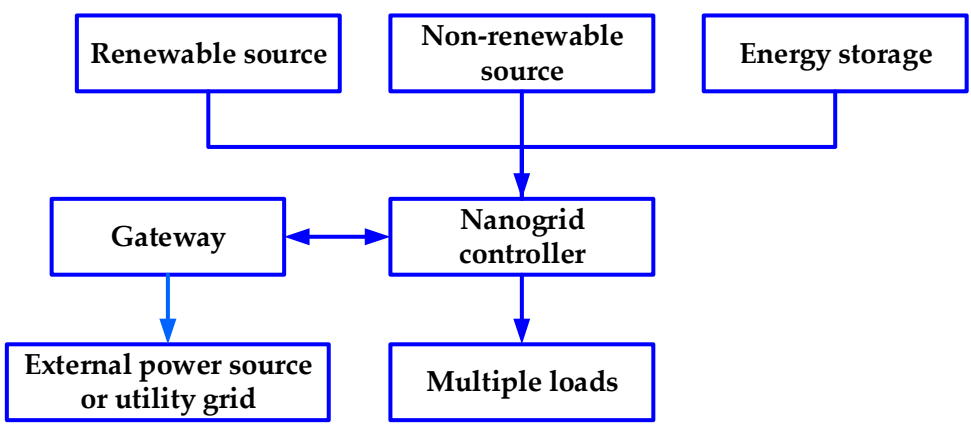

Figure 3. Components of a nanogrid.

Bidirectional flow between the nanogrid, power grid and microgrid is provided by the gateway, which also handles the communication between power networks. Finally, an ESS could be integrated as an optional element in line with its ability to stabilise the network.

Similar to microgrids, nanogrids can be either AC coupled or DC coupled. The DC nanogrid employs a DC-to-DC converter to interface with the DC load. The gateway is based on a bidirectional AC-to-DC converter. On the other hand, the AC nanogrid consists of a DC-AC inverter that takes the DC voltage as an input from the source converter and outputs $230 \mathrm{~V}$. Although the majority of existing loads in both homes and factories are AC, DC nanogrids have the advantage in terms of efficiency and performance factors, though DC nanogrids also have protection issues. The damaging faults which include ground fault and circuit line fault can arise at switching devices, loads and output terminals. They can be curtailed by installing arcing-type circuit breaker protection [14]. A network of nanogrids "Plico project" in western Australia is a good example of community-focused microgrids. It aims to develop a virtual power plant based on residential PV and battery storage systems [27].

\subsubsection{Community Grids}

A CG [21] involves DRES integration to the utility grid together with consumer engagement to facilitate an energy trading mechanism. The architecture of a CG is based on a central community grid controller (CGC), which manages and operates the virtual microgrid. The key aim of the deployment of a CG is to reduce electricity consumption from the grid by utilising more power from DRESs. The focus, however, is on the penetration of DRESs for micro-generation systems and distributed systems without comprising power grid stability [21,24]. Moreover, consumers can actively become energy active citizens and exchange energy within their CG, and also potentially with the transmission grid.

Nonetheless, CGs are also associated with technical problems including generation intermittency, voltage fluctuation, stability, resonances, harmonic distortion, islanding operation and network protection [21]. The voltage fluctuations and generation variability directly affect the active power flow in the distribution networks, both in terms of direction and magnitude. Further, the variation in active and reactive power also affects the voltage 
profile in the distribution feeders. This problem can be resolved using static synchronous compensators (STATCOMs), tap changers, PV inverters, power inverters and energy storage [21].

Stability problems can occur with large or small signal surges. Larger surges are by interactions between different items of equipment in a slowly changing event, while small surges are generated by sudden changes in operating conditions. Unstable behaviour in the distribution grid can cause serious equipment disconnection and disturbances. The impedance criterion in this case can be used to determine small signal instability. The proper selection of protection schemes is also essential for the stable operation of community microgrids. Reasons for improper selection include relay malfunctioning while mis-operations are caused by erroneous operation of the fuse, unsynchronised closing and loss of coordination [21].

\subsubsection{Integrated Community Energy Systems}

A study by Koirala, Koliou [19] explored the development of integrated community energy systems (ICESs) which integrates different combinations of DRESs as an alternate energy system for the transition of the local energy landscape. ICESs are multiproduct and multisource and fulfil the requirements of the energy of the local communities by establishing better synergy between different communities and by integrating the energy sectors. The energy system for ICESs consists of different technological artefacts and decision-making groups and are governed by energy policymakers. They also facilitate energy-related services for large-scale systems, network services and operating reserves using the interconnection and can provide superior community engagement with selfreliance, energy independence and security. The technical challenges discussed in [19] related to the ICESs are highlighted in Table 4.

Table 4. Technological issues of ICESs.

\begin{tabular}{cr}
\hline Challenges & ICESs Role \\
\hline $\begin{array}{c}\text { Intermittency of DRESs, demand response } \\
\text { Load and grid defection }\end{array}$ & $\begin{array}{c}\text { Mitigation of the effect of peaks, load balancing in power, activation of demand } \\
\text { and generation }\end{array}$ \\
\hline Storage & Collective purchasing of community energy storage and household storage devices \\
\hline Energy efficiency & Collective purchasing of insulated energy-efficient appliances and materials \\
\hline Local balancing of demand and supply & Diversity in supply and demand \\
\hline Impact on larger energy system & Load balancing and ICESs increase the penetration of renewables \\
\hline
\end{tabular}

\subsubsection{Smart Energy Systems}

Connected communities can also take advantage of an SES to improve the quality of supply and reliability, the use of local participation of citizens as well as the reduction in cost in terms of energy vectors procurement [22]. SESs can address various socio-technical issues including energy poverty in rural areas and energy autonomy to maintain balance in energy flow between storage and import. It promotes renewable uptake by managing electricity peak demands and reduces GHG emissions. From a technical point of view, an SES addresses demand prediction and data-related issues by placing accurate sensors and loggers for measuring energy demand. Further, SESs can be developed by the approaches outlined below:

Multi-energy approach: This uses various DRESs such as hydrogen, biogas and fossil fuels for electricity cooling/heating loads.

Sharing approach: Multiple users locally share a single energy system through central microgrids powered by different renewable sources that allow the system to use them more efficiently. 
Energy storage: Energy storage stores the excess amount of thermal/electric energy produced.

EV integration: The surplus energy from renewable systems can also be stored in EVs in the smart energy community (SEC) and can be further provided to final users through vehicle to home technology.

NZEB: The NZEB approach allows a high energy performance building to fulfil most energy demands through local DRES.

\subsubsection{Interconnected Multi-Microgrids}

Interconnected multi-microgrids (IMMGs) incorporate multiple individual microgrids closely located and connected to an electrical distribution bus. IMMGs can operate in either the grid-connected mode or the islanded mode. IMMGs also facilitate energy trading with microgrids situated in close proximity, thus avoiding large distance transmission losses. One of the major advantages IMMGs offer is the distributed structure of microgrids, which improves the reliability of the distribution network [13].

The three topologies usually used in IMMGs are radial or star, mesh and daisy chain. In the radial topology, the multi-microgrids form a star arrangement where each microgrid is connected to the main grid directly through a distribution bus at point of energy exchange. One of the key challenges with the radial topology is management of energy and power sharing capability. If the energy exchange with a utility grid is overloaded, the power distribution line can become congested. In daisy chain configuration, the energy flows bidirectionally between the main grid and the microgrid, and also between adjacent microgrids. The energy sharing with other microgrids leads to additional challenges in designing the energy schedule and optimisation techniques with network constraints. Microgrids in mesh topology are interconnected using a communication network and a transmission line. The structure is complex compared with the daisy chain and radial technologies; thus, more intelligent coordination and energy-sharing techniques are required.

\subsubsection{Hybrid Renewable Energy Sources}

Communities can also be connected using HRESs which are specifically built for island and remote village communities. In HRESs, the diesel power plant is the main source of supply (39\%), while the mainland grid contributes $25 \%$ and others $36 \%$. Consequently, hybrid systems based on diesel/wind play a significant role as a source of power (18\%) [20]. A list of hybrid system characteristics for remote villages and islands discussed in [20] are provided in Table 5.

Table 5. Micro-community hybrid grid projects.

\begin{tabular}{|c|c|c|}
\hline Main Activities & Remote Village & Islands \\
\hline Major hybrid system configuration & Batteries/PV/private diesel generator & Wind/diesel power plant/PV \\
\hline Grid connections & $86 \%$ isolated & $71 \%$ isolated \\
\hline Major backup & Batteries & Diesel \\
\hline Renewable penetrations & $\begin{array}{l}\text { For yearly demands up to } 100 \% \text {, lower than } \\
\qquad 2000 \mathrm{kWh} / \text { household }\end{array}$ & $\begin{array}{l}\text { For yearly demands up to } 80 \% \text {, lower } \\
\text { than } 20,000 \mathrm{MWh}\end{array}$ \\
\hline Demand & [1.3-245.3] MWh/year based on evening hours & $\begin{array}{l}\text { Different with geographic sites } \\
{[111-754,000] \text { MWh/year; peak high }} \\
\text { demand-24 h requirements }\end{array}$ \\
\hline Number of houses and demand & $\begin{array}{l}\text { Less than } 50 \mathrm{MWh} / \text { year of demand for } \\
60 \text { houses }\end{array}$ & $\begin{array}{l}\text { When inhabitants increase above } 10,000, \\
\text { the relation of demand is non-linear }\end{array}$ \\
\hline Common configurations & PV/PDG coupled with batteries & Wind/PV/DPP \\
\hline
\end{tabular}




\section{Energy Storage for Community Microgrids}

A community microgrid configuration necessitates the adoption of ESSs as this offers various benefits. From a technical perspective, load demand aggregation generates fewer spikes in load profile in comparison with an individual house, which reduces the battery discharge rate and also decreases the optimum battery capacity. Most importantly, energy storage becomes crucial when the primary source of power is from DRESs, and therefore, to cover the rest of the night demand, more storage is needed if grid consumption is to be avoided [21]. In the case of off-grid CCMs, this implies a large amount of storage. ESSs can address the issue of intermittent generation; hence, efficient storage is still a significant challenge for future microgrids.

The adoption of CES provides power quality, stability to the grid, voltage control, peak demand management and demand load management. From a socio-economic point of view, and along with distributed wind and solar power resources, CES addresses issues of energy efficiency, affordability and mitigation of GHG emissions linked to individual households and communities [17]. Further, utility companies can optimise CES systems for the benefits of the electricity network and wholesale electricity markets. However, the existing CES models (through battery) are costly. CES can open new approaches for energy transition as the community scale introduces electrochemical technologies such as batteries and can increase the awareness of users and communities regarding energy usage and environment.

Several energy storage technologies are discussed by the selected reviews. Conventional lead-acid batteries are the most widely available storage in the market and mainly used in automotive applications and in uninterrupted power supplies for residential and commercial purposes $[16,17,19,25]$. The major benefits of lead-acid are low cost, high efficiency (70-80\%) and long lifetime (5-10 years). However, cycle-lifespan is short (i.e., 500-2000 cycles), which limits the charging capability and provides poor temperature handling $[17,19]$.

Lithium-ion (Li-ion) technology is by far the most rapidly growing and adoptable technology for stationary applications $[19,24,25]$. The success factors are high efficiency $(90-95 \%)$, high energy density $(75-200 \mathrm{Wh} / \mathrm{kg})$, long life and operating cycles, low maintenance, high power capability and better temperature management $\left(-25{ }^{\circ} \mathrm{C}\right.$ to $\left.55^{\circ} \mathrm{C}\right)[16,18,19,24,25]$. The most common identified downside of Li-ion technology is high cost $[17,18]$; however, this is estimated to drop within next decade in line with massive manufacturing. Similarly, flow batteries are used in high-power, large-scale commercial-based systems and offer better efficiency (80-85\%) [17].

Thermal storage systems offer efficient storage with 30-60\% efficiency, better energy density (80-250 Wh/ kg) and low energy consumption and GHG emissions [15-19,25]. Thermochemical heat storage systems have high energy density with minimal loss; however, thermochemical materials incorporated in storage systems for buildings have the drawback of high cost, unsuitable temperature and discharge power $[15,19,25]$.

Hydrogen is also considered a promising technology for mid- to long-term storage because of its high specific energy density $(33 \mathrm{kWh} / \mathrm{kg})$ and energy and power ratings [17]. The process usually involves converting surplus electricity into hydrogen and oxygen through electrolysis; hydrogen can then be used to charge fuel cells. Higher costs of electrolysers and supporting material are disadvantages of this technology $[17,20,25]$. Moreover, water needed, and logistics costs make it an expensive investment. For shortterm standby applications, flywheels are also considered promising [19]; these can stabilise intermittent generation from solar and wind.

Further storage technologies such as compressed air energy storage and pumped hydro storage, regardless of their poor efficiency, carry high capacities with longer lifespans $[16,19,25]$. Superconducting magnetic energy storage yields high efficiency; however, it is still in the demonstration and testing phase [16]. 


\section{Control and Optimisation Methodologies}

Microgrids require different control tasks to guarantee the correct operation of the system. The optimisation of CCMs is no different than conventional microgrids and have also been broadly examined in the literature that focuses on load demand, economic efficiency, GHG emission reduction and control optimisation.

Controls in AC and DC microgrids consist of a hierarchical structure which executes tasks on the basis of multi-agent control $[16,25]$. There are three outer to inner levels of controls; namely, grid, management controller and field [16,25]. At the grid level, a distribution network operator and a market operator are usually functional. At the management level, a microgrid controller manages functions such as frequency regulation, voltage control, grid synchronism, blackouts and optimisation operations. Similarly, at the field level, local controllers are placed in each component of the microgrid (DGs, storage or loads). Local controllers for DGs normally consist of the droop control method, which offers high reliability and does not demand a communication network between DRESs. For intermittent DRESs, non-linear droop control is implemented. Local controllers for storage control the charge and discharge of a battery or other source. One such control method mentioned in [16] is the state of charge (SOC)-based adaptive droop.

In DC microgrids, there are no frequency control or reactive power flow requirements, which makes the grid interfacing task easier. Conversely, frequency must be controlled in AC microgrids, and power electronic components should be synchronised with the grid for stable operation. Phase locked loops are the most common method for AC system synchronisation with the grid.

The voltage balancing requirement is also crucial for microgrids. This is controlled in AC microgrids using reactive compensation devices such as static var compensators or STATCOMs.

AC microgrids' stability is typically affected by the operational mode (on grid/off grid), control topologies, type of DRES and network parameters. The main stability issues identified by [16] include small signal stability, transient stability and voltage stability. Most of these issues can be resolved through improvement in control methodologies for DGs, storage and load.

The following subsections present various control methodologies and their characteristics discussed in the reviewed articles.

\subsection{Energy Management Systems}

Energy management systems (EMS) in IMMGs are used for controlling generation and energy consumption. Each individual microgrid consists of a renewable source, ESS, residential/commercial loads and EMS, which autonomously controls and manages energy. Additionally, the microsource controllers are responsible for controlling the ESS, and the load controllers for managing controllable loads. All of these components are interconnected using a rigid communication infrastructure [13].

Distributed optimisation EMS techniques for IMMGs include dual decomposition (DD), game theory and the alternating direction method of multipliers (ADMM). In a DD optimisation technique, the microgrid and distributed system operator (DSO) are owned by different groups and, based on their objectives and policy, schedule non-renewable and renewable DGs.

Game theory provides a strong tool to attain cooperative and non-cooperative power control strategies in interconnected microgrids. This approach uses each microgrid to attain more benefits than operating alone under well-designed policies. In IMMGs, a cooperative approach is usually preferred. The literature in [13] covered various game theory algorithms proposed in order to gain benefits for microgrids. Nash bargaining is used for effective and fair energy trading between IMMGs. Similarly, coalitional game theory optimises energy sharing and trading in smart households while also decreasing the total cost of microgrids. In non-cooperative game theory, the Nash equilibrium involves competition among purchasing microgrids for every microgrid with a diverse energy 
demand in the IMMG. It is generally applicable in situations where all microgrids in the network simultaneously share energy on an equal basis.

In contrast, the ADMM algorithm carries superior convergence properties while achieving an optimal power schedule and can be used for distributed microgrids. ADMM, like other strategies, was used by various studies to optimise power flow and real-time energy management.

\subsection{Building Energy Management System}

A BEMS uses a complex method to monitor and control the building energy usage. A BEMS may include controllers that read input parameters such as weather information, building insights, renewable system and other parameters to regulate the whole system to bring maximum efficiency. Decisions for efficiency are made based on energy consumption and cost factors. To ensure the integrity of BEMSs, FDD methods are also used to sense and isolate faults and to protect BEMSs from further damage or loss. FDD processes are usually categorised into model-based FDD, signal-based FDD, knowledge-based FDD, active FDD and hybrid FDD.

Presently, the control strategies such as on-off control, proportional integral derivative (PID) control and rule-based control, as stated in Hannan, Faisal [15], exhibit drawbacks in terms of stability. Therefore, a model-based control system in a BEMS is implemented in which control parameters of the building are processed mathematically. A model predictive control (MPC) approach for a BEMS was also studied and the three aspects of MPC identified were problem formulation, control architecture and implementation type.

IoE technology in BEMS controllers regulates bidirectional information and electricity flow. The IoE blends the characteristics of smart grid and the Internet of Things (IoT) [15]. The IoT has several real-life applications that require telemetric assistance, while a smart grid specifically provides bidirectional communication between BEMS and the grid, and also controls and monitors energy generation. Since the IoE establishes communication between these two aforementioned units, it also utilises information from the metering. The IoE has various control nodes and routers that can be used for network solutions. The possible system architecture of the IoE posits a control centre in the middle and other objects such as DRESs, sensors and storage are connected to the controlling object through the internet, which then makes decisions based on inputs and commands.

There are several challenges that are noteworthy with regard to BEMSs, including the unreliability of renewable system operation, internet security, scalability and cost. Monitoring data from the BEMS may have corrupted and be missing data values; thus, advanced deep learning techniques may be implemented to predict future estimated values. Similarly, security and privacy techniques such as blockchain in the EMS can be utilised to secure the network. Optimisation techniques for energy efficiency, energy storage materials, non-linear electronics interfaces and power quality issues are other future research directions to be explored [15].

\subsection{Nanogrid Controllers}

The topology for nanogrids uses a centralised controller [21], which receives values from sensors and performs actions for optimising the power. In the decentralised approach, nodes communicate to each other and operate independently from a centralised controller. The hybrid distributed control has combined characteristics of centralised and distributed control. The few control techniques for nanogrids mentioned in the studies are given below:

Ad hoc nanogrid: This is a type of distributed control is used where there is no access to a national power grid.

Cost function: Uses a central control and takes advantage of fluctuations in power grid prices for implementing the DSM.

Predictive control: A hybrid central control makes decisions based on historical information. 
Flattening peak electricity demand: Assists to reduce the amount of power purchased from a power grid.

Droop control: A technique used for controlling the level of voltage on the demand and supply management sides.

Further, a nanogrid network can be used to connect multiple nanogrids to form a microgrid, creating a larger power system. The nanogrid focuses on the hierarchical approach to distribute power from the nanogrid to a microgrid to the utility grid. One of the advantages of this approach is that it can handle intermittent power outages. In addition, bidirectional power sharing balances the grid and the communication layer, making the network more secure, and it can collect statistics on power usage. These advantages lead to overall financial benefits and grid stability; however, the central control unit makes the system susceptible to failure and makes it dependent on high bandwidth communication architecture.

\subsection{Building-Integrated Microgrids}

The objective of the building-integrated microgrid control is to minimise operational costs while satisfying constraints such as grid reliability and equipment stability. The centralised control collects data from microgrid components and applies an optimisation algorithm to achieve optimal control decisions in the central unit. In distributed control, there is no central agent, and the optimisation algorithm is applied locally. Centralised control has good performance in small-scale microgrids, and the decentralised approach operates well for large-scale microgrids [25]. The control strategies of building microgrids and optimisation techniques given in [25] are summarised below.

Rule-based control: These are based on conditional commands, based on IF-THEN statements and are easy to implement because of simplicity in syntax. Applications of rule-based control given in [25] consist of a commercial building automation system and ESS-based microgrids. Rule-based control has the convenience of implementation without control; however, it does not perform effectively compared with advanced and intelligent control systems.

Optimal control and multi-objective optimisation: Control decisions in optimal control are made by resolving an optimisation issue and applying the optimal control outcome. Optimisation problems are solved within the framework of a large control scheme; for example, MPC. The objective of optimal control generally is to decrease the total operational cost of the microgrid. On the other hand, multi-objective optimisation is beneficial when there are two separate objectives: for instance, total cost and reduction in GHG emissions.

Decision variables: These variables imply parameters that can be referenced by a controller to make an operational decision. Examples include battery charging/discharging power, reactive power from DG, SOC, controllable loads and temperature baselines.

Agent-based control: This is a decentralised approach based on multiple agents that is worthwhile to implement in microgrid energy management. Moreover, it is useful in conditions where a fully formulated optimisation problem becomes unfeasibly difficult, or there is no knowledge of the full system model.

MPC: This widely used control strategy in microgrids depends totally on the system dynamic model. The model utilised is a linear dynamic model. MPC has the capability to forecast future events and perform on that information in the present.

Optimisation techniques were also covered by Fontenot and Dong [25], as given below.

Linear programming: In this optimisation technique, a linear objective function is minimised over a group of decision variables within a group of linear constraints. It is restricted to cost functions and constraints that are linear in the decision variables.

Non-linear programming: In this, neither constraints nor objective functions are linear in terms of decision variables. Non-linear programming can be significantly more complex to solve than linear programming, particularly if the objective function and constraints are non-convex. 
Dynamic programming: The optimisation problem in dynamic programming is distributed into sub-problems in a recursive manner. In microgrids, where each system state depends on the former state, sub-problems may be resolved in reverse, commencing with the known state, until the initial (desired unknown) state is resolved.

Stochastic programming: This integrates random variables into optimisation problems so as to identify uncertainties in model data. For instance, stochastic programming can account for irregularities in load demand, DRES generation and energy costs.

Metaheuristics: Metaheuristics is a high-level method designed to discover processes that can lead to satisfactory results to optimisation issues. Metaheuristics are highly useful in situations when system information is not available, or where the solution set to a problem is unrealizably huge.

\subsection{Advanced Controls for Energy Storage and EVs}

The current literature has also focused on advanced control methods for enhancing building energy performance with battery storage and EVs. These advanced controls can be classified into individual and coordinated controls that emphasise the optimisation of a single building and multiple buildings, respectively.

In an individual control approach, the process of individual building energy storage or charging rates of EVs are optimised independently. After that, the individual energy storage or EV charging loads are aggregated to obtain the aggregated level of performance. However, this aggregated performance is not optimised. Different methods for optimisation such as an MPC approach, a mixed-integer non-linear programming algorithm and a multi-objective non-linear inversion-based control strategy were discussed for individual controls [18].

The coordinated control approach can further be categorised into bottom-up and topdown approaches. In a bottom-up approach, the optimisation of processes of individual energy storage and the individual EV charging rates are executed in sequential succession based on the aggregated results of the previously optimised energy storage or EVs. In a top-down approach, the optimisation objective encompasses aggregate level performance. To attain the acquired performance at the aggregated level, the operations of individual energy storage or the individual EV charging rates are coordinated.

Some of the methods mentioned in [18] for coordinated control include Deep Reinforcement (DR) Learning to learn the optimal behaviour via a trial and error-based method, collaborative DR control, an adaptive bi-level decision model, a two-stage adaptive robust optimisation-based collaborative operation approach, a coordinated charging method and the MPC method. One drawback of the coordinated approach is that computational complexity rises with the increasing quantity of energy storage devices or EVs.

\subsection{Hybrid Systems Controllers}

Investigation of the load interval curves illustrates that load levels remain intermediate normally for the greater part of the year. However, high peaks are encountered less often and survive for relatively short intervals. CCMs have advantages of handling shortinterval high peaks; however, long duration peaks would require large storage systems, which are not economically viable [17]. In such cases, a combination of technologies (i.e., hybrid systems) can be preferred as they can meet community energy requirements at much lower costs than individual systems. Solutions of an exemplar hybrid system could be collated from these technologies based on system requirements: flywheels/super capacitors for high power, lead-acid/Li-ion batteries for stable power and energy, and flow batteries/hydrogen for energy storage. One downside of this method is that technical configurations and optimization processes for hybrid systems can be considerably more complicated than for a single-technology design.

Moreover, in a community setup, the CGC in [21] overviews grid operation, performs power and energy matching, stabilises and controls the amplitudes of different parameters and facilitates the interaction of prosumers and the utility operator in energy trading. 


\section{Energy Sharing: A Major Incentive for Community}

Energy sharing inside the community or a cluster of buildings improves the selfconsumption rate while mitigating electricity demand from the grid. To unlock the benefits of energy sharing, a specific energy-sharing solution is required for the transfer of the energy equivalent from one prosumer to another. Based on existing technology, this sharing is implemented mainly on AC networks; however, researchers also recommend sharing on DC microgrids in line with the large availability of DC-powered appliances [18]. In its simplest form, the basic configuration for energy sharing in a CCM connects to a number of buildings where surplus renewable energy or energy from a central storage is shared between buildings or communities that are low in demand and also exported to the main grid $[13,14,19,22]$. This process is often metered to maintain transactions and billing for incentivising prosumers [23]; other sharing configurations include embedded networks and BTM. The roof space for accommodating PV panels can belong to the owners' corporation, the owner or the construction developer. Based on these shared configurations, there are different forms of energy trading, most notably blockchain, tariff-based and energy leasing. Moreover, surplus PV energy can be shared using local energy trading, a basic form of peer-to-peer trading calculated via the reconciliation of total exported and grid-imported energy [23]. To amplify this community energy trading, it is desirable to have a graphical user interface platform for ease of use.

In a multi-owned building with a CCM, issues such as cost and benefit allocation might appear. Similarly, the capital cost of shared systems in a CCM could be complex because of its different distribution nature among consumers, building owners, utility companies and third-party companies.

Scaling up energy storage for multiple buildings or units increases value. For instance, in a multi-residential building or community where loads are usually asynchronous, shared storage capacity could be less than the sum of individual storages in the case where each user installs their own battery. The literature mainly considers active sharing; however, research should consider reactive power behaviour to improve system reliability. Moreover, energy management schemes can be highly suitable for energy sharing. The literature identified few projects with implemented energy trading between consumers; in the NEXT21 project, end-users are able to share and trade energy with each other [22].

In the solar to buildings (S2B) mobility model [18], surplus PV energy is shared between several buildings to reduce dependency on the main grid and efficiently utilise overall PV energy. The buildings in the S2B mobility model are connected to a central sharing microgrid that delivers the excessive PV energy from one building to other buildings with high consumption. This shared microgrid is also connected to the main grid in the case of insufficient PV generation. Research conducted by [18] reviewed extensions of the conventional S2B model to solar to buildings, vehicles and storage (S2VBS).

The adoption of EVs that rely on solar mobility models can also contribute effectively to reducing GHG emissions. The solar to vehicle functions through the concept of combining a standard grid-connected PV system with EVs. A local controller manages the energy flow between solar, grid and EV. In some instances, the integration of buildings and EV could work perfectly following a standard method. Electricity produced by rooftop PV panels primarily supplies the house loads and then charge the EV batteries. In the case of surplus generation, energy is exported to the grid. In models with building, storage and EVs, the EV batteries are allowed to feed electricity to the building or utility grid.

Further, plug-in hybrid electric vehicles (PHEVs) could minimise a building's total energy costs by scheduling and optimising the charging-discharging of batteries. In other examples, a retired EV battery (REVB) model was investigated on the basis of the fading capacity model of lithium battery, and a multi-objective algorithm non-dominated sorting genetic algorithm II (NSGA-II,) generated the Pareto set of optimal solutions. This developed NSGA-II method in a residential building indicated that a hybrid energy system with PV-hydrogen-REVB is a satisfactory way to display REVBs' residual capacities. In addition, a building-to-vehicle-to-building model enables the bidirectional exchange of electricity 
between EV batteries and buildings. In this model, the application of bidirectional EV charging and discharging enables PV energy sharing among a cluster of buildings. Such methods for energy sharing significantly improve PV power utilisation and brings financial and environmental benefits.

The metrics mainly used for evaluating the performance of a S2VBS model are environment, energy and economy. Energy performance is assessed using various parameters including loss of power supply possibility (LPSP) and potential energy waste possibility (PEWP). The LPSP assesses the possibility of whole energy system power loss among commonly used metrics. The PEWP evaluates the energy usage efficiency of the modelled renewable energy system. The capacity factor analyses PV power generation. The economic performance assessment of PV systems is carried out using the simplest economic indicator, which is cost of energy. Similarly, the net present value ascertains the investment profitability. Further, the payback period is another generally used indicator for economic analysis. The profitability index estimates the investment profitability by quantifying the amount created per unit of investment. Lastly, environmental performance is assessed using GHG emissions and carbon intensity.

Figure 4 presents a summarised illustration of CCM components, features and functionalities. Moreover, a list of CCM projects included in review articles is also included in Appendix D.

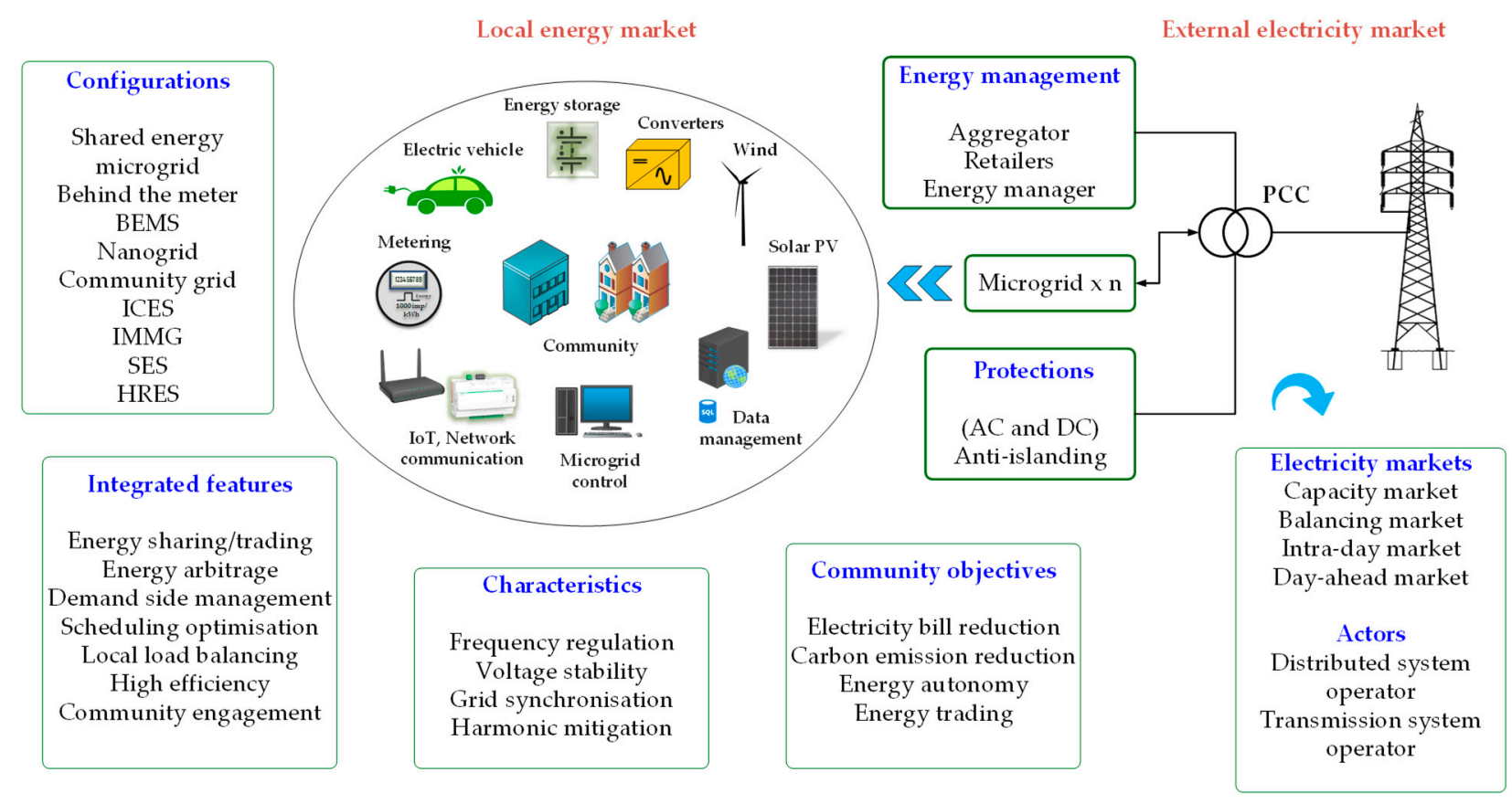

Figure 4. Features and functions of CCMs based on included studies.

\section{Barriers and Opportunities}

\subsection{Regulatory Issues}

Regulatory frameworks for CCMs necessitate a set of supportive rules and principles to address socio-techno-economic and institutional issues to pave the way for successful microgrid implementation. Most often, profitability from DRESs is highly dependent on regulatory frameworks of a particular dominion [23], coupled with consumer engagement $[17,24]$. Nevertheless, the major barrier in deployment of CCMs is incumbents supporting centralised systems. However, considering distributed systems beyond PCC, energy management between microgrids and DSOs becomes complex in line with the interconnectedness of individual microgrids, and synchronous operation with active/reactive power flows between microgrids, varying loads and grids [13]. Varying levels of power generation intermittency because of weather can be harmful for the network, owing to the 
inadequacy of monitoring, diagnosing and maintaining the system [15]. Moreover, the penetration of renewables in the grid causes voltage fluctuations and resonances $[15,21]$. Alongside these, the other main factors hindering the proliferation of community microgrids include high grid interconnection costs, additional protection requirements considering large PV integration, feed-in-tariffs and islanding issues $[16,19,23]$. Moreover, the shortage of public and/or private locations to install power units also presents challenges for community microgrids.

Actors in the energy market, including households, have diverse interests; for example, end-users expect low-cost efficient energy. Energy service providers benefit from energyefficient operation and management of local generation. Meanwhile, aggregators envisage business models that optimise profits and flexibility in the capacity markets. Regulators, which generally include governments, transmission system operators (TSOs), DSOs and policymakers, seek to maintain a low-carbon, low-cost balance of supply and demand for consumers while also distributing energy to the residential network and grid [19].

In terms of development consent, installing PV storage systems in established jurisdictions requires permission from the state or the council and, in some cases, restrictions may apply due to shading from newly constructed buildings [23]. Similarly, for the purpose of revenue generation, the strata company or owners' corporation, which manage energy trading, are required to be registered as service providers/retailers. This entails a series of operational and cost restrictions that may discourage the adoption of DER, especially in multi-residential apartments [23].

To achieve an energy-efficient and sustainable system, price design is also pivotal for providing subsidies; ancillary services, and services-based markets such as capacity markets, balancing markets as well as day-ahead energy markets [19]. Community systems supported by DSOs are often restricted by regulators from operating DGs and ESSs to inhibit them from competing with independent generators in the wholesale electricity market $[17,22]$. Regulators want service providers to enter the capacity market while strata or owners consider a much cheaper and cleaner community solution [23].

From another perspective, the installation of an embedded system or shared energy microgrid $[28,29]$ can affect the revenue stream for the network because the fee is charged for energy distributed at one connection point rather than several individual connections through large tariffs.

Similarly, on the policy side, incentives such as subsidies and feed-in tariffs can boost the uptake of renewables that may participate in ancillary services [17,22,23], whereas taxes and levies on CCMs conversely could affect installations $[17,18,23]$. In some instances, the lack of consumption data to implement optimised energy planning should not be overlooked [22].

Emphasis should be given to consolidate universal standards; for instance, in terms of technical rules, IEEE 1547 (DRES interconnection with the grid) is considered the gold standard for microgrids. Similarly, regulations are needed for DC microgrids. The existence of regulatory frameworks, and a good understanding of such, are essential for the effective commissioning of microgrids [16,19,22,23]. Global examples mentioned in [24] enjoy the full value proposition due to the absence of market and regulatory frameworks; however, techno-economic challenges remain. If grid support services are ensured, projects such as gridSMART in the US, which provides a distributed management controller and aggregated setup, could be a better model of utility scale community projects $[17,25]$.

To unlock the full potential of microgrids, a shared learning platform should be practiced to coalesce community groups, policymakers and regulators and decipher the policies and regulatory frameworks that may help in overcoming the barriers $[17,19,22]$.

\subsection{Opportunities}

One of the major advantages after installation of CCM is that it reinforces the economics in various ways. Imported grid electricity is reduced by the integration and utilisation of DRESs and due to this, there are always open opportunities for new busi- 
nesses. If a grid is properly managed, it may result in incentives as well as cost savings which can be relayed to the level of consumers.

CCMs can facilitate a utility grid during peak demand. Advanced control methodologies discussed in Section 6 with the help of system monitoring can shave peak loads, reducing peak hour costs, and can also defer pricey maintenance and upgrades to transformers and distribution feeders. Aggregated power generation by CCMs could also support ancillary services, for instance, voltage and frequency regulation, which may further generate revenue possibilities.

CCMs can offer cheap electricity costs, a resilient microgrid and may also supply energy in emergency situations. Through highly resilient and highly reliable systems, energy-related businesses such as data centres and high-tech industries can be attracted.

\section{Conclusions and Future Directions}

This review presents a guideline and summary for the researchers on existing microgrids, configurations and technologies used and sets forth future recommendations helpful for policymakers and industries, who are laying the groundwork for commissioning CCMs. Notably, the rapid review methodology was applied to the research area of microgrids, which play a key role in the abatement of global GHG emissions and dependence of communities on utility grids-two burning issues of this decade.

Existing microgrids, either AC or DC, operate using a centralised approach (storage and control), which performs well for small microgrids. AC microgrids have numerous advantages at the PCC. Similarly, DC microgrids offer several benefits, especially for longdistance transmission and lower costs of controllers and metering. On the other hand, AC protection systems are more economical than DC protections. The existing protection schemes for microgrids are designed for a customised solution; more research is needed to design protection schemes for universal microgrid design. Since microgrids are becoming more advanced and complex, the performance of the centralised approach is increasingly unstable. Thus, there is a need for further exploration of the decentralised approach.

The intermittent and volatile characteristics of the DRES with dynamic loads in the $\mathrm{CCM}$ present new challenges in designing optimal control and scheduling techniques in power systems. Load demand and DRES selection in building intelligent microgrids vary across consumers and utilities; therefore, these bilateral requirements must be managed through the energy system. Further, optimisation techniques for resolving stochasticity, energy efficiency, storage materials, non-linear communication and power quality issues including reactive power flow are critical future research directions. In terms of energy trading, focus has been given to active trading and sharing; nevertheless, reactive power should also be considered an essential element of calculations for gaining overall stability.

For efficient load operation, optimisation methods such as online algorithms have importance in energy scheduling; these online algorithms should reduce computational complexity. IoE-based BEMSs offer energy savings and GHG reductions but pose several challenges, including internet security, scalability and cost. Moreover, missing data points, spurious values and discrepancies can interfere with the energy management process, particularly as concerns security and privacy. Central control systems (at the multibuilding scale) are a critical component of CCMs, providing maximum benefits to the grid, dwelling owners and consumers, whereas decentralised control offers "plug-and-play" performance. Intriguingly, nanogrid controllers may act as decentralised controllers, share energy and facilitate DSM techniques, and can also form a microgrid in an interconnected topology.

Designing and orchestrating storage technologies is a significant challenge in terms of economics and efficiencies; thus, future research should develop cost-effective highly efficient ESSs technologies [20]. Li-ion technology is expected to be a widely adopted battery technology for CCMs. For community setup, CES as a model can open new doors for the energy transition as community-scale microgrids will incorporate storage technologies such as batteries and increase awareness across users and communities regarding energy consumption and environmental aspects. Community batteries can essentially reduce 
capacity by half in comparison with individual battery systems, owing to the favourable impact of demand aggregation. Battery storages with HRESs for remote villages are a good choice on technical and economic grounds. Nevertheless, the existing models running on battery storage are expensive, and other forms of hybrid sources are required to fulfil at least $50 \%$ of the energy demand. It is also evident from implemented examples that DC microgrids are a gradually emerging technology and could be much more efficient than AC microgrids. However, the design of DC microgrids requires further exploration to develop advanced systems for large-scale deployment.

CCMs enable engagement between local communities by means of mutual purchasing, combined ownership arrangements and the integration of various sectors such as electricity, heating, cooling and gas. CCMs may significantly enhance future energy systems if there is an assurance of financial incentives and a consensus between different actors; notably, regulatory authorities, policymakers, government and community.

Notwithstanding, future research should incorporate advanced building coordinated controls and optimisation algorithms such as agent-based modelling and occupancy models in microgrids for optimising energy usage to obtain improved self-sufficiency and maximum economic gains.

Author Contributions: Conceptualization, M.M.S.; methodology, M.M.S.; software, M.M.S.; validation, M.M.S., G.M.M.; formal analysis, M.M.S.; investigation, M.M.S.; resources, M.M.S.; writingoriginal draft preparation, M.M.S.; writing—review and editing, M.M.S., G.M.M.; visualization, M.M.S.; supervision, G.M.M.; project administration, M.M.S. and G.M.M.; funding acquisition, G.M.M. All authors have read and agreed to the published version of the manuscript.

Funding: This research was funded by the Australian Renewable Energy Agency (ARENA) as part of its Research and Development Programme.

Institutional Review Board Statement: Not applicable.

Informed Consent Statement: Not applicable.

Conflicts of Interest: The authors declare no conflict of interest.

\section{Nomenclature}

$\begin{array}{ll}\text { AC } & \text { Alternating current } \\ \text { ADDM } & \text { Alternating direction method of multipliers } \\ \text { AMSTAR2 } & \text { A Measurement Tool to Assess Systematic Reviews version 2 } \\ \text { B2V } & \text { Building to vehicle } \\ \text { BEMS } & \text { Building energy management system } \\ \text { BTM } & \text { Behind the meter } \\ \text { CCM } & \text { Community connected microgrids } \\ \text { CES } & \text { Community energy storage } \\ \text { CGC } & \text { Community grid controller } \\ \text { COVID-19 } & \text { Coronavirus disease 2019 } \\ \text { CP } & \text { Common property } \\ \text { DC } & \text { Direct current } \\ \text { DD } & \text { Dual decomposition } \\ \text { DG } & \text { Distributed generators } \\ \text { DR } & \text { Deep Reinforcement } \\ \text { DRES } & \text { Distributed renewable energy systems } \\ \text { DSM } & \text { Demand-side management } \\ \text { DSO } & \text { Distributed system operator }\end{array}$




$\begin{array}{ll}\text { EMS } & \text { Energy management system } \\ \text { ESS } & \text { Energy storage systems } \\ \text { EV } & \text { Electric vehicles } \\ \text { FDD } & \text { Fault detection and diagnosis } \\ \text { GHG } & \text { Greenhouse gas } \\ \text { HRES } & \text { Hybrid Renewable Energy Systems } \\ \text { HVDC } & \text { High voltage direct current } \\ \text { ICES } & \text { Integrated community energy systems } \\ \text { IEEE } & \text { Institute of Electrical and Electronic Engineers } \\ \text { IGBT } & \text { Insulated-gate bipolar transistors } \\ \text { IMMG } & \text { Interconnected multi-microgrids } \\ \text { IoE } & \text { Internet of Energy } \\ \text { IoT } & \text { Internet of Things } \\ \text { LC } & \text { Inductance-Capacitance } \\ \text { Li-ion } & \text { Lithium-ion } \\ \text { LPSP } & \text { Loss of power supply possibility } \\ \text { MPC } & \text { Model predictive control } \\ \text { NSGA-II } & \text { Non dominated sorting genetic algorithm II } \\ \text { NZEB } & \text { Net zero energy buildings } \\ \text { PCC } & \text { Point of common coupling } \\ \text { PEWP } & \text { Potential energy waste possibility } \\ \text { PHEV } & \text { Plug-in hybrid electric vehicles } \\ \text { PID } & \text { Proportional integral derivative } \\ \text { PRISMA } & \text { Preferred Reporting Items for Systematic reviews and Meta-Analyses } \\ \text { PV } & \text { Photovoltaic } \\ \text { REVB } & \text { Retired EV battery } \\ \text { RoB } & \text { Risk of bias } \\ \text { S2B } & \text { Solar to buildings } \\ \text { S2BVS } & \text { Solar to building, vehicle and storage } \\ \text { SEC } & \text { Smart energy community } \\ \text { SES } & \text { Smart energy systems } \\ \text { SLR } & \text { Systematic literature reviews } \\ \text { SOC } & \text { State of charge } \\ \text { STATCOMs } & \text { Static synchronous compensators } \\ \text { TSO } & \text { Transmission system operators } \\ \text { US } & \text { United States } \\ & \end{array}$


Appendix A

Table A1. Search String and Filters Applied to the Academic Databases.

Database

\section{Filters Applied}

AND DOCTYPE(re) AND PUBYEAR > 2009 AND PUBYEAR $<202$

AND (LIMIT-TO (SUBJAREA,"ENER") OR LIMIT-TO (SUBJAREA,"ENGI") OR LIMIT-TO (SUBJAREA,"MULT")) AND (LIMIT-TO (EXACTSRCTITLE,"Renewable And Sustainable Energy Reviews")
OR LIMIT-TO (EXACTSRCTITLE,"Applied Energy") OR LIMIT-TO (EXACTSRCTITLE,"Energy And Buildings") OR LIMIT-TO (EXACTSRCTITLE,"Renewable Energy") OR LIMIT-TO

(EXACTSRCTITLE,"Energies") OR LIMIT-TO (EXACTSRCTITLE,"Energy") OR LIMIT-TO

(EXACTSRCTITLE,"Energy Conversion And Management") OR LIMIT-TO (EXACTSRCTITLE,"International Journal Of Energy Research") OR LIMIT-TO (EXACTSRCTITLE,"Journal Of Energy Storage") OR LIMIT-TO (EXACTSRCTITLE,"Solar Energy") OR LIMIT-TO (EXACTSRCTITLE,"Sustainability Switzerland") OR

LIMIT-TO (EXACTSRCTITLE,"Sustainable Cities And Society") OR LIMIT-TO (EXACTSRCTITLE,"Building

And Environment") OR LIMIT-TO (EXACTSRCTITLE,"Journal Of Power Sources") OR LIMIT-TO

(EXACTSRCTITLE,"Wiley Interdisciplinary Reviews Energy And Environment") OR LIMIT-TO OR "photovoltaic" OR "microgrid" OR "microgrid*" OR "distributed" OR "integrated") AND TITLE-ABS-KEY(batter OR battery OR storage OR "energy storage" OR "battery storage") AND TITLE-ABS-KEY("building*” OR

"muntident OR "condos" OR "suite" OR "villa*" OR "multi-unit") AND

TITLE-ABS-KEY("systematic review" OR "systematic

literature review" OR review OR "meta analysis" OR "meta-analysis"))

(EXACTSRCTIE "Advances In Building Energy Research") OR LIMIT-TO (EXACTSRCTITLE"Building Simulation") OR LIMIT-TO (EXACTSRCTITLE,"Buildings") OR LIMIT-TO (EXACTSRCTITLE "Electronics Switzerland") OR LIMIT-TO (EXACTSRCTITLE,"Energy And Environment") OR LIMIT-TO

(EXACTSRCTITLE,"Energy And Environmental Science") OR LIMIT-TO (EXACTSRCTITLE,"International Journal Of Electrical Power And Energy Systems") OR LIMIT-TO (EXACTSRCTITLE,"International Journa Of Low Carbon Technologies") OR LIMIT-TO (EXACTSRCTITLE,"Journal Of Cleaner Production")) AND (LIMIT-TO (EXACTKEYWORD,"Solar Energy") OR LIMIT-TO (EXACTKEYWORD,"Energy Storage") OR LIMIT-TO (EXACTKEYWORD,"Energy Efficiency") OR LIMIT-TO (EXACTKEYWORD,"Energy Utilization") OR LIMIT-TO (EXACTKEYWORD,"Renewable Energy Resources") OR LIMIT-TO

(EXACTKEYWORD,"Building") OR LIMIT-TO (EXACTKEYWORD,"Solar Power Generation") OR LIMIT-TO (EXACTKEYWORD,"Sustainable Development") OR LIMIT-TO (EXACTKEYWORD,"Energy Conservation") OR LIMIT-TO (EXACTKEYWORD,"Renewable Energies") OR LIMIT-TO

(EXACTKEYWORD,"Renewable Energy Source") OR LIMIT-TO (EXACTKEYWORD,"Energy

Management") OR LIMIT-TO (EXACTKEYWORD,"Renewable Energy") OR LIMIT-TO (EXACTKEYWORD,"Smart Power Grids") OR LIMIT-TO (EXACTKEYWORD,"Solar Power") OR LIMIT-TO (EXACTKEYWORD "Performance Assessment") OR LIMIT-TO (EXACTKEYWORD,"Solar Buildings") OR LIMIT-TO(EXACTKEYWORD,"Energy Storage Systems") OR LIMIT-TO

(EXACTKEYWORD,"Optimization") OR LIMIT-TO (EXACTKEYWORD,"Photovoltaic System") OR LIMIT-TO (EXACTKEYWORD,"Smart Grid") OR LIMIT-TO (EXACTKEYWORD,"Literature Reviews") 
Table A1. Cont.

Database Search String

((TOPIC: (((C((("solar" OR “solar PV") OR “PV") OR “solar*”) OR “photovoltaic*”) OR "microgrid") OR “microgrid") OR "distributed*") OR "integrated") AND TOPIC: ((()batter* OR battery) OR storage) OR "energy storage") OR "battery storage" $))$ AND TOPIC: $\left(\left(\left(\left(()\left(\left(\left({ }^{\prime \prime} b u i l d i n g * "\right.\right.\right.\right.\right.\right.\right.$ OR

Web of Science "multi-residential") OR "apartment*") OR community) OR "communit*) OR “dwelling*") OR "storey") OR "multi-family") OR “condom") OR "suite ${ }^{* \prime \prime}$ OR “villa*") OR

"multi-unit")) AND TOPIC: (((("systematic review" OR

"systematic literature review") OR review) OR "meta analysis") OR "meta-analysis"))

\section{Filters Applied}

OR LIMIT-TO(EXACTKEYWORD,"Renewable Energy Systems") OR LIMIT-TO

(EXACTKEYWORD,"Renewable Resource") OR LIMIT-TO (EXACTKEYWORD,"Demand-side Management") OR LIMIT-TO (EXACTKEYWORD,"Electricity Generation") OR LIMIT-TO (EXACTKEYWORD,"Review") OR LIMIT-TO (EXACTKEYWORD,"Reviews") OR LIMIT-TO (EXACTKEYWORD,"Storage") OR LIMIT-TO (EXACTKEYWORD,"Sustainability") OR LIMIT-TO (EXACTKEYWORD,"Building Applications") OR LIMIT-TO (EXACTKEYWORD,"Demand Analysis") OR LIMIT-TO (EXACTKEYWORD,"Demand Response") OR LIMIT-TO (EXACTKEYWORD,"Energy") OR

LIMIT-TO (EXACTKEYWORD,"Intelligent Buildings") OR LIMIT-TO (EXACTKEYWORD,"Power Generation") OR LIMIT-TO (EXACTKEYWORD,"Electric Batteries") OR LIMIT-TO

(EXACTKEYWORD,"In-buildings") OR LIMIT-TO (EXACTKEYWORD,"Micro Grid") OR LIMIT-TO (EXACTKEYWORD,"Photovoltaic") OR LIMIT-TO (EXACTKEYWORD,"Photovoltaic Systems") OR LIMIT-TO (EXACTKEYWORD,"Renewable Energy Generation") OR LIMIT-TO

(EXACTKEYWORD,"Residential Building") OR LIMIT-TO (EXACTKEYWORD,"Use Of Renewable

Energies") OR LIMIT-TO (EXACTKEYWORD,"Zero Energy Buildings") OR LIMIT-TO

(EXACTKEYWORD,"Battery Storage") OR LIMIT-TO (EXACTKEYWORD,"Building Energy Consumption") OR LIMIT-TO (EXACTKEYWORD,"Community Energy") OR LIMIT-TO (EXACTKEYWORD,"Design Method") OR LIMIT-TO (EXACTKEYWORD,"District Energy Systems"))

Refined by: WEB OF SCIENCE CATEGORIES: (GREEN SUSTAINABLE SCIENCE TECHNOLOGY OR ENGINEERING ELECTRICAL ELECTRONIC OR MANAGEMENT OR AUTOMATION CONTROL SYSTEMS OR ENGINEERING ENVIRONMENTAL OR ENGINEERING MULTIDISCIPLINARY OR ENVIRONMENTAL STUDIES OR MULTIDISCIPLINARY SCIENCES OR EDUCATION EDUCATIONAL RESEARCH OR EDUCATION SCIENTIFIC DISCIPLINES OR ENGINEERING MANUFACTURING) AND DOCUMENT TYPES: (REVIEW) AND SOURCE TITLES: (RENEWABLE SUSTAINABLE ENERGY REVIEWS

OR RENEWABLE ENERGY OR CLEAN TECHNOLOGIES AND ENVIRONMENTAL POLICY OR JOURNAL OF MODERN POWER SYSTEMS AND CLEAN ENERGY OR SUSTAINABLE CITIES AND SOCIETY OR SUSTAINABILITY OR CSEE JOURNAL OF POWER AND ENERGY SYSTEMS OR JOURNAL OF CLEANER PRODUCTION OR CURRENT OPINION IN GREEN AND SUSTAINABLE CHEMISTRY OR ENERGY EDUCATION SCIENCE AND TECHNOLOGY PART A ENERGY SCIENCE AND RESEARCH OR BUILDING AND ENVIRONMENT OR ENVIRONMENTAL PROGRESS SUSTAINABLE ENERGY OR IET GENERATION TRANSMISSION DISTRIBUTION OR IEEE ACCESS OR ADVANCED SUSTAINABLE SYSTEMS OR INTERNATIONAL JOURNAL OF ELECTRICAL POWER ENERGY SYSTEMS OR SMART SCIENCE OR INTERNATIONAL JOURNAL OF PRECISION ENGINEERING AND MANUFACTURING GREEN TECHNOLOGY OR INTERNATIONAL JOURNAL OF RENEWABLE ENERGY DEVELOPMENT IJRED) Timespan: 2010-2020. Indexes: SCI-EXPANDED, SSCI, A\&HCI, CPCI-S, CPCI-SSH, BKCI-S, BKCI-SSH, ESCI, CCR-EXPANDED, IC. 
Table A1. Cont.

Database Search String

("solar" OR "solar PV" OR “PV" OR "solar"” OR "photovoltaic ${ }^{* \prime}$ OR "microgrid" OR "microgrid*" OR "distributed" OR "integrated") AND (batter* OR battery OR storage OR "energy storage" OR "battery storage") AND ("building*" OR "multi-residential" OR "apartment" OR community OR “communit*" OR “dwelling*" OR "storey" OR "multi-family" OR "condos" OR "suite*" OR "villa*" OR

"multi-unit") AND ("systematic review" OR "systematic

literature review" OR review OR "meta analysis" OR "meta-analysis")

\section{Filters Applied}

AND stype.exact("Conference Papers \& Proceedings" OR "Reports" OR "Working Papers" OR "Scholarly Journals") AND at.exact("Literature Review" OR “Review") AND la.exact("English" OR “English") AND (pub.exact("Energy, Sustainability and Society" OR "Clean Technologies and Environmental Policy" OR "Sustainability" OR "Journal of Modern Power Systems and Clean Energy" OR "Frontiers in Energy" OR

"Sustainability Science" OR "Current Sustainable/Renewable Energy Reports" OR "Energies" OR "European Journal of Information Systems") AND at.exact("Literature Review") AND subt.exact("literature reviews"

OR "reviews" OR "sustainability" OR "systematic review" OR “energy" OR “energy storage" OR "sustainable development" OR "optimization" OR "renewable energy" OR "technology") AND la.exact("ENG") AND pd(20100101-20201027) AND PEER(yes))

("All Metadata":"solar" OR "solar PV" OR "PV" OR "solar*" OR "photovoltaic*" OR "microgrid" OR "microgrid*" OR "distributed*" OR “integrated") AND “All Metadata": batter* OR battery OR storage OR "energy storage" OR "battery storage") AND “All Metadata":"building*" OR

"multi-residential" OR "apartment" OR community OR

"communit*" OR “dwelling*" OR "storey" OR "multi-family" OR “condos" OR "suite*" OR “villa*" OR "multi-unit") AND "All Metadata":"systematic review" OR "systematic literature review" OR review OR "meta analysis" OR "meta-analysis")
Filters Applied: JournalsIEEE AccessProceedings of the IEEEIEEE Communications Surveys \& TutorialsEngineering \& TechnologyIEEE Transactions on Industry

ApplicationsIEEE Transactions on Power ElectronicsIEEE Transactions on Industrial ElectronicsDesign Issuesreviewsdata analysispower gridsdistributed power generationpower convertors2010-2020 


\section{Appendix B}

Table A2. AMSTAR2 Assessment Checklist.

\begin{tabular}{c} 
Questions \\
\hline $\begin{array}{c}\text { Question 1. Have reviewers } \\
\text { clearly described research }\end{array}$
\end{tabular}

questions and inclusion criteria?

Question 2. Did the article explicitly state about design of review methods before it was initiated and did the article vindicate any variation from the protocol?

Question 3. Did the review authors elucidate their study selection?

Question 4. Was literature search technique applied by the review authors?

Question 5. Had authors independently carry out study selection?

\section{Decision Rules and Comments}

$1=$ yes = components of

PICO (Population, Intervention, Comparator group, and Outcome).

$0.5=$ unsure $/$ moderately $=$ undecided between yes and no, drawing on the information given in the review.

$0=$ no $=$ no such information explicitly given.

$1=$ yes $=$ protocol was written by the authors that consisted of ALL of the following: search technique, review question, inclusion/exclusion method, RoB evaluation.

$0.5=$ unsure $/$ moderately $=$ protocol was written by the authors that consisted of ALL of the following: search technique, review question, inclusion/exclusion method, RoB evaluation.

$0=$ no $=$ not included any systematic review design.

$1=$ yes $=$ reasons of the study selection provided in the review.

$0.5=$ unsure $/$ moderately $=$ multiple online sources or single online source. Undecided between yes and no, drawing on the information given in the article.

$0=$ no $=$ just a single online source OR no search additionally conducted.

1 = yes = searched minimally 2 databases, keyword and/or search technique included, applied filtered on, e.g., language, country AND checked the references/bibliography, searched for grey literature, searched under 24 months of review completion.

$0.5=$ unsure/moderately = searched at least 2 databases, keyword and/or search technique included, applied filtered on, e.g., language, country.

$$
0=\text { no }=\text { no relevant information given } \text {. }
$$

$1=$ yes = any of these: minimum of two reviewers independently agreed on the selection of articles and decided on which articles to incorporate OR two authors chosen a specimen of article and accomplished at least $80 \%$ consensus, with the rest chosen by another author.

$0.5=$ unsure $/$ moderately $=$ undecided between yes and no, drawing on the data given in the article.

$0=$ no $=$ exclusively one author performed study selection or no details of authors' participation in study selection.

$1=$ yes $=$ any of these: minimum of two reviewers agreed to extract data from the articles OR two authors performed data extraction from articles and accomplished at least $80 \%$ consensus, with the rest chosen by another author.

Question 6. Had authors independently carry out data extraction?
$0.5=$ unsure $/$ moderately $=$ undecided between yes and no, drawing on the data given in the article.

$0=$ no $=$ one author selected the articles or no details of authors' participation in extracting the data.

$1=$ yes $=$ presented details of all potentially excluded articles from the review AND for each article, provided reasons for article exclusion.

Question 7. Had authors provided details of the excluded articles and reasons for excluding the article?

$0.5=$ unsure $/$ moderately $=$ provided details of all excluded studies from the review but for each study, did not provide reasons for excluding articles from the review.

$0=$ no $=$ no list of excluded studies.

$1=$ yes = components of PICO (Population, Intervention, Comparator group, and Outcome).

Question 8. Had authors delineate the embedded articles sufficiently?
$0.5=$ unsure /moderately = components of PICO (Population, Intervention,

Comparator group, and Outcome) concisely explained, or with little information. Undecided between yes and no, drawing on the data given in the article. 
Table A2. Cont.

\begin{tabular}{c} 
Questions \\
\hline Question 9. Had authors employ \\
an acceptable technique for \\
assessing the RoB in articles \\
incorporated in the review?
\end{tabular}

Question 10. Had authors provided the information on funding source for the articles?

Question 11. Had authors provided suitable methods for statistical combination of results, If meta-analysis was performed?

Question 12. Had authors evaluate the probable effects of RoB in individual articles on the meta-analysis results If meta-analysis was performed?

\section{Question 13. Had authors} elucidated

RoB in individual articles when explaining the review results? heterogeneity noticed in the results, did authors provide a

discussion or satisfactory

Question 15. Had authors conduct sufficient investigation of article bias and explained its potential effects on the results If performed quantitative analysis was performed?
Question 14. For any interpretation?

\section{Decision Rules and Comments}

$1=$ yes $=$ RoB assessment was explicitly mentioned in the included articles.

$0.5=$ unsure $/$ moderately $=$ undecided between yes and no, drawing on the data given in the articles. RoB referred OR not adequately analysed (e.g., more than one source of bias was found; however, not all were analysed).

$0=$ no $=$ RoB assessment was not mentioned in included articles.

1 = yes = provided information on funding sources for individual articles.

$0.5=$ unsure/moderately $=$ funding sources given for articles included in the review, or provided details on few articles. Undecided between yes and no, drawing on the data given in the article.

$0=$ no $=$ no description on the funding sources for individual articles.

$1=$ yes $=$ the authors provided reasons for integrating the data using meta-analysis AND employed a suitable method to collate outcomes and amended any heterogeneity

AND researched the reasons of any diversity or amended any heterogeneity or contradiction.

$0.5=$ unsure $/$ moderately $=$ conditions for yes only moderately completed. Undecided between yes and no, drawing on the data given in the article.

$0=$ no $=$ no clarification of meta-analysis or improper statistical techniques were employed for quantitatively collating and data analysis, moreover heterogeneity was not analysed.

$\mathrm{N} / \mathrm{A}=$ not applicable $=$ meta-analysis was not performed .

1 = yes $=$ selected only low RoB studies.

$0.5=$ unsure $/$ moderately $=$ undecided between yes and no, drawing on the information given in the article.

$0=$ no $=$ the probable effect of RoB not assessed.

$\mathrm{N} / \mathrm{A}=$ not applicable $=$ meta-analysis was not performed.

$1=$ yes $=$ merely low RoB articles were included OR potential impact of RoB on the results were discussed.

$0.5=$ unsure $/$ moderately $=$ undecided between yes and no, drawing on the data given in the article.

$0=$ no $=$ no clarification of the likely effect of RoB in individual articles.

$1=$ yes $=$ heterogeneity in the results had no potential OR in the case heterogeneity was found, the reviewers investigated those sources and explained the effect on the results.

$0.5=$ unsure $/$ moderately $=$ undecided between yes and no, drawing on the data given in the article.

$0=$ no $=$ no elaboration or explanation of heterogeneity.

$1=$ yes $=$ the authors performed statistical or graphical experiments for publication bias and explained the prospects and extent of effects of publication bias.

$0.5=$ unsure $/$ moderately $=$ multiple online sources without additional sources OR a single online source and one additional source. Undecided between yes and no, drawing on the data given in the article.

$0=$ no $=$ tests for publication bias was not performed and neither potential impact of publication bias was explained.

$\mathrm{N} / \mathrm{A}=$ not applicable $=$ meta-analysis was not performed.

$1=$ yes $=$ no competing interests were reported by the authors OR the reviewers declared their sources of funding and how the authors arranged probable conflicts of interest.

Question 16. Had authors mention any likely root of conflict of interest, including any funding they received for performing the review?
$0.5=$ unsure $/$ moderately $=$ undecided between yes and no, drawing on the data given in the article.

$0=$ no $=$ statement on competing interests and sources of funding were not provided, neither how authors arranged probable conflicts of interest. 
Appendix C

Table A3. Summary of Key Findings from Reviewed Articles.

\begin{tabular}{|c|c|c|}
\hline Author & Key Findings & Recommendations \\
\hline Zou, Mao [13] & $\begin{array}{l}\text { - IMMGs generate better results in distributed architecture, along with energy } \\
\text { trading facilitation within adjacent microgrids whilst mitigating } \\
\text { transmission losses. Consequently, the grid operates under less stress } \\
\text { conditions. } \\
\text { Depending upon locality, IMMGs can work both in islanded or } \\
\text { grid-connected mode. }\end{array}$ & $\begin{array}{l}\text { - Optimal scheduling techniques are challenging due to the intermittent } \\
\text { characteristics of DRESs alongside dynamic loads in the microgrids. } \\
\text { IMMGs should handle varying load characteristics from the consumers' and } \\
\text { - } \quad \text { utilities' end. } \\
\text { Reactive power besides active power should also be considered in } \\
\text { optimization scheduling techniques to enhance the robustness and } \\
\text { reliability of the power system. }\end{array}$ \\
\hline Burmester, Rayudu [14] & $\begin{array}{l}\text { - Nanogrids operate on a reduced capacity than conventional microgrids; } \\
\text { nevertheless, several nanogrids can be coupled through gateway controllers } \\
\text { to form a large microgrid. } \\
\text { They facilitate energy trading between consumers / prosumers and various } \\
\text { nanogrids. } \\
\text { DC nanogrids have an edge over AC microgrids in terms of efficiency due } \\
\text { to less power conversion steps. DC nanogrids can be highly adaptable since } \\
\text { the majority of electronic appliances are DC powered. }\end{array}$ & $\begin{array}{l}\text { - More demonstrational projects are required to test nanogrids to understand } \\
\text { consumer centric incentives. Moreover, nanogrid research may help energy } \\
\text { retailers to strategize demand-side management. }\end{array}$ \\
\hline Hannan, Faisal [15] & $\begin{array}{l}\text { - Key technologies used in IoE-based BEMSs are energy routers, battery } \\
\text { storage and plug-and-play interfaces. } \\
\text { - Low energy efficiency, environment, storage materials and power quality } \\
\text { are major issues in commissioning of IoE-based BEMSs. } \\
\text { - Significant energy savings and GHG emission reduction can be achieved } \\
\text { from an IoE-based BEMS. }\end{array}$ & $\begin{array}{l}\text { - IoE-based BEMSs require scalable, stable, and localized systems for the } \\
\text { future improvement of building energy utilization. } \\
\text { An efficient BEMS also demands an advanced system for processing large } \\
\text { amounts of data and the maintenance of privacy. } \\
\text { - An IoE-based BEMS has significant potential for future development } \\
\text { depending on the integration of cost-effective and energy-efficient DRESs. }\end{array}$ \\
\hline Planas, Andreu [16] & $\begin{array}{l}\text { - The AC microgrids provide better protection at PCC whilst they are more } \\
\text { economical than DC protections. } \\
\text { DC microgrids provide low-cost metering and better power quality } \\
\text { considering long-distance transmission. } \\
\text { - For decreasing installation costs, AC microgrids are economical for big } \\
\text { loads (e.g., industries and power plants) whilst DC microgrids work better } \\
\text { for locations with more DC loads (e.g., offices). }\end{array}$ & $\begin{array}{l}\text { - At present, small microgrids are designed with centralized control. } \\
\text { However, as technology progresses, the new systems are getting more } \\
\text { complex; therefore, a centralized approach may cause instability. Research is } \\
\text { required to investigate decentralize options. Existing protection schemes are } \\
\text { modelled for a customized system design; therefore, universal protection } \\
\text { schemes for microgrids should be introduced. }\end{array}$ \\
\hline
\end{tabular}


Table A3. Cont.

\begin{tabular}{|c|c|c|}
\hline Author & Key Findings & Recommendations \\
\hline Parra, Swierczynski [17] & $\begin{array}{l}\text { - Energy efficiency characteristics such as self-consumption, electricity } \\
\text { demand load shifting and management are key drivers of CES rollout. } \\
\text { PV generation produces more economic value than demand load shifting } \\
\text { due to the difference in retail and wholesale electricity tariffs. } \\
\text { - The successful implementation of CES also ensures absolute energy } \\
\text { management, incentive-based community engagement, community rights } \\
\text { over grid ownership and a stable policy framework. }\end{array}$ & $\begin{array}{l}\text { - For a significant role in future energy systems, interaction among different } \\
\text { actors, authorities and governments are required. The adoption of CES may } \\
\text { also be escalated by the provision of economic incentives and improved } \\
\text { regulatory frameworks formed by policymakers. } \\
\text { Battery technology is still expensive; therefore, CES should rely on } \\
\text { energy-efficient technology. }\end{array}$ \\
\hline Huang, Zhang [18] & $\begin{array}{l}\text { With the integrated operation of shared microgrids, PV, ESSs, EVs and } \\
\text { design of advanced controls, S2BVS mobility models can provide optimal } \\
\text { performance including increased self-consumption and energy autonomy. } \\
\text { Moreover, energy sharing is a key characteristic of the S2BVS model, which } \\
\text { can exploited by employing the better coordination of buildings, storage } \\
\text { and vehicles. }\end{array}$ & $\begin{array}{l}\text { - The existing methods seldom incorporate EV control in building energy } \\
\text { management. This includes the charging/discharging of EV batteries. } \\
\text { Future studies are required to design advance control for integrating EVs } \\
\text { with electrical storage. } \\
\text { - Advanced DC systems for large scale systems are needed in future research. } \\
\text { Buildings clusters must be well designed to capitalize the full potential of } \\
\text { energy sharing. }\end{array}$ \\
\hline Koirala, Koliou [19] & $\begin{array}{l}\text { - ICESs leverage advanced community engagement with autonomous energy, } \\
\text { power reliability and security. Moreover, using the interconnection, they } \\
\text { also enable network services and operating reserves. } \\
\text { ICESs influence various actors as they interact with different systems. } \\
\text { Therefore, policies need to be designed in agreement with all stakeholders } \\
\text { for equal distribution of costs and incentives. }\end{array}$ & $\begin{array}{l}\text { - Challenges in centralized energy systems (socio-economic, technical, } \\
\text { environmental and institutional) should be overcome. Therefore, } \\
\text { well-designed business models, institutional factors and regulatory } \\
\text { frameworks are required before the integration of ICESs. } \\
\text { - Using different demonstrational projects, quantitative assessment using } \\
\text { empirical data is recommended to increase the adaption of ICESs. }\end{array}$ \\
\hline Neves, Silva [20] & $\begin{array}{l}\text { - The standard configuration of hybrid systems in islands and remote } \\
\text { communities is wind/photovoltaic/DPP and photovoltaic/PDG coupled } \\
\text { with battery storage in villages. } \\
\text { For island applications, the design of an ESS is a big challenge from } \\
\text { economics and efficiencies perspectives. }\end{array}$ & $\begin{array}{l}\text { - Accurate facts and figures are required for demand estimation and power } \\
\text { security. } \\
\text { - System optimisation requires design methodology and tools considering } \\
\text { real investments projections. } \\
\text { Renewable autonomy of } 50 \% \text { will be hard to achieve, unless storage } \\
\text { technology is standardised for HRESs. }\end{array}$ \\
\hline Rosado and Khadem [21] & $\begin{array}{l}\text { - Much higher DRES penetration will be required in future community grids. } \\
\text { This penetration can be enabled by coordinated microgrid operation, energy } \\
\text { storage to mitigate DRES intermittency, microgrid protection and the usage } \\
\text { of sophisticated controllers. } \\
\text { Impactful communication between the community grid controller and } \\
\text { distribution network is important for neutralizing the disturbance from the } \\
\text { distribution network. }\end{array}$ & $\begin{array}{l}\text { - Advanced protections systems need improved communication interfaces } \\
\text { with new functionalities such as grid parameters detection and } \\
\text { synchronization. }\end{array}$ \\
\hline
\end{tabular}


Table A3. Cont.

\begin{tabular}{|c|c|c|}
\hline Author & Key Findings & Recommendations \\
\hline Ceglia, Esposito [22] & $\begin{array}{l}\text { - The community considers the collective interest by prioritizing the location } \\
\text { of resources confined to a specific location and also keeping a } \\
\text { socio-technical network. } \\
\text { Generally, the DRES for energy production at a particular region is not } \\
\text { shared with the population. Therefore, in the SEC modelling strategy, } \\
\text { community acceptance is a major problem to address. } \\
\text { The absence of appropriate energy laws may result in consumer } \\
\text { dissatisfaction. }\end{array}$ & $\begin{array}{l}\text { - Future studies should evaluate and focus on the legislative context of } \\
\text { energy communities' experimental proposals from various geographical } \\
\text { and economic perspectives. } \\
\text { Energy community design can achieve a grid of communities which may } \\
\text { improve the energy market management and environmental benefits of a } \\
\text { particular jurisdiction. }\end{array}$ \\
\hline Roberts, Bruce [23] & $\begin{array}{l}\text { - PV installation in apartments needs considerable coordination between } \\
\text { prosumers and actors to share cost incentives from BTM or embedded } \\
\text { network configurations. } \\
\text { Despite regulatory, governance and financial barriers, practical models for } \\
\text { multi-residential apartments exist; however, a shared consortium can aid } \\
\text { prosumers in determining feasible opportunities. }\end{array}$ & $\begin{array}{l}\text { - Generally, communities have unanimity over joint decisions; other actors } \\
\text { and policymaking bodies should also line up with communities' interest. } \\
\text { A dearth of energy data in apartments is still an obstacle to discern the PV } \\
\text { installations. From the regulatory point of view, data availability could be } \\
\text { essential in the decision-making process. }\end{array}$ \\
\hline Olgyay, Coan [24] & $\begin{array}{l}\text { - An efficient and reliable grid-connected system with PV with an ESS } \\
\text { generating low GHG emissions can be obtained using CCs. } \\
\text { CCs can achieve high reliability, reduce the capacity requirements and } \\
\text { provide various value streams in energy bill reduction and cost savings. }\end{array}$ & $\begin{array}{l}\text { - The diversity in building type and load with DRESs will facilitate multiple } \\
\text { value streams. } \\
\text { - Shared resources (e.g., shared PV and energy storage) connected to multiple } \\
\text { buildings could possibly offer improved lifecycle costs than single dwelling } \\
\text { due to low maintenance costs and high resource utilization. }\end{array}$ \\
\hline Fontenot and Dong [25] & $\begin{array}{l}\text { - Due to the intermittency of DRESs and consumer occupancy behavior } \\
\text { scheduling, the optimization of a microgrid becomes complex. } \\
\text { The complexity of a given model ensures the accuracy while it also increases } \\
\text { computational load. Moreover, smart meter data have consumer privacy } \\
\text { and microgrid security issues. }\end{array}$ & $\begin{array}{l}\text { - Rigid optimization strategies will become imperative as design models of } \\
\text { microgrids are becoming complex. Agent-based modeling, occupancy } \\
\text { models and integration of building-to-grid systems need to be integrated in } \\
\text { microgrid. }\end{array}$ \\
\hline
\end{tabular}




\section{Appendix D}

Table A4. List of Community Microgrid Projects across the Globe.

\begin{tabular}{|c|c|c|c|}
\hline Project & Country & System & Description \\
\hline Seasons at Ontario & United States & $\begin{array}{l}140 \mathrm{~kW} \text { solar PV on rooftop of } 80 \text { unit multi-family buildings. PV } \\
\text { generation is allocated to the common areas and benefits are shared } \\
\text { between the building owner and tenants. }\end{array}$ & $\begin{array}{l}\text { A near-zero-energy building was demonstrated that integrates solar } \\
\text { PV with the motivation to decrease energy costs and operational } \\
\text { expenses by increasing energy efficiency and demand response } \\
\text { strategies. }\end{array}$ \\
\hline $\begin{array}{l}\text { Lancaster Virtual Power } \\
\text { Plant }\end{array}$ & United States & $\begin{array}{l}10 \mathrm{MW} \text { PV and } 5 \mathrm{MW} \text { energy storage fitted on schools, homes and } \\
\text { other facilities. The expanded construction development would } \\
\text { install a } 125 \mathrm{~kW} / 500 \mathrm{kWh} \text { flywheel system fucntioning as a virtual } \\
\text { power plant. }\end{array}$ & $\begin{array}{l}\text { A virtual power plant which aims to optimise DRESs to obtain } \\
\text { reveneue generation, increase cost savings, and acheive grid stability. }\end{array}$ \\
\hline Peña Station NEXT & United States & $\begin{array}{l}\text { A microgrid with } 1 \mathrm{MW} \text { PV, } 2 \mathrm{MWh} \text { battery; } 1.6 \mathrm{MW} \text { DC } \\
\text { grid-connected solar carport system installed in a 100-building } \\
\text { mixed-use community built on } 382 \text { acre land. The microgrid enables } \\
\text { multiple stakeholders to share the assets and the incentives from } \\
\text { PV-BESS. }\end{array}$ & $\begin{array}{l}\text { The installed microgrid improves system stability by offering } \\
\text { frequency and voltage regulation, whilst energy storage and demand } \\
\text { response decreases existing grid infrastructural costs. }\end{array}$ \\
\hline Reynolds Landing & United States & $\begin{array}{l}800 \mathrm{~kW} \text { PV, } 600 \mathrm{kWh} \text { battery microgrid instlaled on } 62 \text { single-family } \\
\text { dwellings. }\end{array}$ & $\begin{array}{l}\text { A microgrid with the help of controller, home energy management } \\
\text { system and DRESs provides grid service and efficient performance for } \\
\text { customers. }\end{array}$ \\
\hline Isle au Haut & United States & $\begin{array}{l}250 \mathrm{~kW} \text { solar PV array, } 1000 \mathrm{kWh} \text { battery storage; diesel generator } \\
\text { and thermal storage capability installed in an island. }\end{array}$ & $\begin{array}{l}\text { Project incorporates a blockchain-based energy network supported by } \\
\text { a metering system. }\end{array}$ \\
\hline Alkimos Beach & Australia & $\begin{array}{l}250 \mathrm{~kW} \text { PV and } 1.1 \mathrm{MWh} \text { battery storage installed on more than } 100 \\
\text { residential homes. }\end{array}$ & $\begin{array}{l}\text { The retail model demostrates that the integration of DRESs with } \\
\text { digital technologies give benefits to consumers, energy retailers, } \\
\text { housing developers and network operators. }\end{array}$ \\
\hline gridSMART project & United States & $\begin{array}{l}25 \mathrm{~kW} \text { PV and } 25 \mathrm{kWh} \text { Li-ion battery storage as well as } 1 \mathrm{MW} \mathrm{PV} \\
\text { with } 6 \mathrm{MWh} \text { sodium sulphur battery installed on a } 150 \text { square mile } \\
\text { area. }\end{array}$ & $\begin{array}{l}\text { Alongside DRESs, the microgrid incorporates different components } \\
\text { such as community battery, reactive control and metering, which will } \\
\text { be integrated with data centre, demand response, dynamic pricing as } \\
\text { well as plug-in hybrid vehicles. }\end{array}$ \\
\hline Kelsterbach & Germany & $\begin{array}{l}50 \mathrm{~kW} \text { and } 135 \mathrm{kWh} \text { Li-ion battery storage installed on individual } \\
\text { houses. }\end{array}$ & $\begin{array}{l}\text { The microgrid increases self-consumption and optimises combined } \\
\text { heat and power storage. }\end{array}$ \\
\hline
\end{tabular}


Table A4. Cont.

\begin{tabular}{|c|c|c|c|}
\hline Project & Country & System & Description \\
\hline CES for Grid Support & United States & $\begin{array}{l}25 \mathrm{~kW} \text { PV and } 50 \mathrm{kWh} \text { Li-ion battery storage installed on } 20 \text { units of } \\
\text { individual houses. }\end{array}$ & $\begin{array}{l}\text { The project showcases a microgrid with peak shaving capability, as } \\
\text { well as voltage support and remote monitoring when integrated to the } \\
\text { grid. }\end{array}$ \\
\hline Feldheim & Germany & $\begin{array}{l}81.1 \mathrm{MW} \text { wind, } 2.25 \mathrm{MWp} \text { solar and a } 500 \mathrm{kWe} / 500 \mathrm{kWt} \text { biomass } \\
\text { plant for district heating and storage; battery storage of } 10 \mathrm{MWh} \\
\text { built for providing frequency control services to a TSO and powers } \\
\text { up to } 37 \text { households. }\end{array}$ & $\begin{array}{l}\text { The system meets all of its local load demand and sends the remaining } \\
\text { generation back to the grid. }\end{array}$ \\
\hline Smart Energy City & Japan & $\begin{array}{l}27,000 \mathrm{~kW} \text { PV and } 2000 \mathrm{EVs} \text { installed in } 4000 \text { smart houses with } \\
\text { A home energy management system. }\end{array}$ & $\begin{array}{l}\text { This community microgrid supplies residential demand through } \\
\text { DRESs and meets } 80 \% \text { of the net load demand. }\end{array}$ \\
\hline $\begin{array}{l}\text { Wiltshire Wildlife } \\
\text { Community Energy }\end{array}$ & Switzerland & $\begin{array}{l}\text { Ground mounted } 1 \mathrm{MW} \text { and } 9.1 \mathrm{MW} \text { PV system powering } \\
\text { approximately } 500 \text { houses. }\end{array}$ & $\begin{array}{l}\text { The project promotes sustainability by introducing DRESs in the } \\
\text { microgrid. }\end{array}$ \\
\hline Sifnos Island Cooperative & Greece & $2 \mathrm{MW}$ PV and 6.9 MW wind farm. & $\begin{array}{l}\text { By utilising DRESs, the project demostrates an autonomous renewable } \\
\text { system and sustainable future for the energy community. }\end{array}$ \\
\hline Kalbarri Microgrid & Australia & $\begin{array}{l}\text { 1.6 MW supplied by wind farm, } 1 \mathrm{MW} \text { from rooftop PV panels } \\
\text { whilst 3.5 MW will be supplied by battery storage } \\
\text { (capacity of } 4.5 \mathrm{MWh} \text { ). }\end{array}$ & $\begin{array}{l}\text { One of Australia's biggest microgrids installed in the coastal town of } \\
\text { Kalbarri which operates entirely in renewable mode, drawing energy } \\
\text { from wind farm and residential PV panels. }\end{array}$ \\
\hline Plico Project & Australia & $\begin{array}{l}\text { Nanogrids and microgrids for } 250+\text { homes with } 6.6 \mathrm{~kW} \text { PV and } 7.2 \\
\text { kWh battery storage systems. }\end{array}$ & $\begin{array}{l}\text { On reaching } 1000 \text { households, the virtual power plant will be able to } \\
\text { provide } 6.5 \mathrm{MW} \text { peak solar, } 9.6 \mathrm{GWh} / \text { year and mitigate } 7 \text { kilo tones of } \\
\text { GHG emissions every year. }\end{array}$ \\
\hline
\end{tabular}




\section{References}

1. Gomes, I.; Melicio, R.; Mendes, V. A novel microgrid support management system based on stochastic mixed-integer linear programming. Energy 2021, 223, 120030. [CrossRef]

2. Lenhart, S.; Araújo, K. Microgrid decision-making by public power utilities in the United States: A critical assessment of adoption and technological profiles. Renew. Sustain. Energy Rev. 2021, 139, 110692. [CrossRef]

3. Tollefson, J. COVID curbed carbon emissions in 2020-But not by much. Nat. Cell Biol. 2021, 589, 343. [CrossRef]

4. IEA. Global CO2 Emissions in 2019. 2020. Available online: https://www.iea.org/articles/global-co2-emissions-in-2019 (accessed on 30 March 2021).

5. Summa, S.; Tarabelli, L.; Ulpiani, G.; Di Perna, C. Impact of Climate Change on the Energy and Comfort Performance of nZEB: A Case Study in Italy. Climate 2020, 8, 125. [CrossRef]

6. $\quad$ Eon, C.; Breadsell, J.; Byrne, J.; Morrison, G. The Discrepancy between As-Built and As-Designed in Energy Efficient Buildings: A Rapid Review. Sustainability 2020, 12, 6372. [CrossRef]

7. Kumar, D.S.; Gandhi, O.; Rodríguez-Gallegos, C.D.; Srinivasan, D. Review of power system impacts at high PV penetration Part II: Potential solutions and the way forward. Sol. Energy 2020, 210, 202-221. [CrossRef]

8. Rosales-Asensio, E.; de Simón-Martín, M.; Borge-Diez, D.; Blanes-Peiró, J.J.; Colmenar-Santos, A. Microgrids with energy storage systems as a means to increase power resilience: An application to office buildings. Energy 2019, 172, 1005-1015. [CrossRef]

9. Murty, V.V.S.N.; Kumar, A. Multi-objective energy management in microgrids with hybrid energy sources and battery energy storage systems. Prot. Control. Mod. Power Syst. 2020, 5, 1-20. [CrossRef]

10. Ganann, R.; Ciliska, D.; Thomas, H. Expediting systematic reviews: Methods and implications of rapid reviews. Implement. Sci. 2010, 5, 56. [CrossRef] [PubMed]

11. Lagisz, M.; Samarasinghe, G.; Nakagawa, S. Rapid Reviews for the Built Environment-Methodology and Guidelines; CRC LCL: Sydney, Australia, 2018.

12. Shea, B.J.; Reeves, B.C.; Wells, G.; Thuku, M.; Hamel, C.; Moran, J.; Moher, D.; Tugwell, P.; Welch, V.; Kristjansson, E.; et al. AMSTAR 2: A critical appraisal tool for systematic reviews that include randomised or non-randomised studies of healthcare interventions, or both. BMJ 2017, 358, j4008. [CrossRef]

13. Zou, H.; Mao, S.; Wang, Y.; Zhang, F.; Chen, X.; Cheng, L. A Survey of Energy Management in Interconnected Multi-Microgrids. IEEE Access 2019, 7, 72158-72169. [CrossRef]

14. Burmester, D.; Rayudu, R.; Seah, W.; Akinyele, D. A review of nanogrid topologies and technologies. Renew. Sustain. Energy Rev. 2017, 67, 760-775. [CrossRef]

15. Hannan, M.A.; Faisal, M.; Ker, P.J.; Mun, L.H.; Parvin, K.; Mahlia, T.M.I.; Blaabjerg, F. A Review of Internet of Energy Based Building Energy Management Systems: Issues and Recommendations. IEEE Access 2018, 6, 38997-39014. [CrossRef]

16. Planas, E.; Andreu, J.; Garate, J.I.; de Alegría, I.M.; Ibarra, E. AC and DC technology in microgrids: A review. Renew. Sustain. Energy Rev. 2015, 43, 726-749. [CrossRef]

17. Parra, D.; Swierczynski, M.; Stroe, D.I.; Norman, S.; Abdon, A.; Worlitschek, J.; O’Doherty, T.; Rodrigues, L.; Gillott, M.; Zhang, X.; et al. An interdisciplinary review of energy storage for communities: Challenges and perspectives. Renew. Sustain. Energy Rev. 2017, 79, 730-749. [CrossRef]

18. Huang, P.; Zhang, X.; Copertaro, B.; Saini, P.; Yan, D.; Wu, Y.; Chen, X. A Technical Review of Modeling Techniques for Urban Solar Mobility: Solar to Buildings, Vehicles, and Storage (S2BVS). Sustainability 2020, 12, 7035. [CrossRef]

19. Koirala, B.P.; Koliou, E.; Friege, J.; Hakvoort, R.A.; Herder, P.M. Energetic communities for community energy: A review of key issues and trends shaping integrated community energy systems. Renew. Sustain. Energy Rev. 2016, 56, 722-744. [CrossRef]

20. Neves, D.; Silva, C.A.; Connors, S. Design and implementation of hybrid renewable energy systems on micro-communities: A review on case studies. Renew. Sustain. Energy Rev. 2014, 31, 935-946. [CrossRef]

21. Rosado, S.P.; Khadem, S.K. Development of Community Grid: Review of Technical Issues and Challenges. IEEE Trans. Ind. Appl. 2018, 55, 1171-1179. [CrossRef]

22. Ceglia, F.; Esposito, P.; Marrasso, E.; Sasso, M. From smart energy community to smart energy municipalities: Literature review, agendas and pathways. J. Clean. Prod. 2020, 254, 120118. [CrossRef]

23. Roberts, M.; Bruce, A.; MacGill, I. Opportunities and barriers for photovoltaics on multi-unit residential buildings: Reviewing the Australian experience. Renew. Sustain. Energy Rev. 2019, 104, 95-110. [CrossRef]

24. Livingood, W.; Olgyay, V.; Coan, S.; Webster, B. Connected Communities: A Multibuilding Energy Management Approach; National Renewable Energy Laboratory: Golden, CO, USA, 2020. [CrossRef]

25. Fontenot, H.; Dong, B. Modeling and control of building-integrated microgrids for optimal energy management-A review. Appl. Energy 2019, 254, 113689. [CrossRef]

26. Syed, M.M.; Morrison, G.M.; Darbyshire, J. Energy Allocation Strategies for Common Property Load Connected to Shared Solar and Battery Storage Systems in Strata Apartments. Energies 2020, 13, 6137. [CrossRef] 
27. PV-Magazine. Plico Energy Plans Expansion after \$4 m Financial Injection. 2021. Available online: https://www.pv-magazineaustralia.com/2021/01/08/plico-energy-plans-expansion-after-4m-financial-injection/ (accessed on 6 June 2021).

28. Syed, M.M.; Hansen, P.; Morrison, G.M. Performance of a shared solar and battery storage system in an Australian apartment building. Energy Build. 2020, 225, 110321. [CrossRef]

29. Syed, M.M.; Morrison, G.M.; Darbyshire, J. Shared Solar and Battery Storage Configuration Effectiveness for Reducing the Grid Reliance of Apartment Complexes. Energies 2020, 13, 4820. [CrossRef] 